\title{
A mixed model approach for evaluating yield improvements in interspecific hybrids of shrub willow, a dedicated bioenergy crop
}

Eric S. Fabio ${ }^{\mathrm{a}}$, Armen R. Kemanian ${ }^{\mathrm{b}}$, Felipe Montes ${ }^{\mathrm{b}}$, Raymond O. Miller ${ }^{\mathrm{c}}$, and Lawrence B. $\operatorname{Smart}^{\mathrm{a}^{*}}$

${ }^{a}$ Horticulture Section, School of Integrative Plant Science, Cornell University, New York State Agricultural Experiment Station, Geneva, NY, 14456, USA

${ }^{\mathrm{b}}$ Department of Plant Science, The Pennsylvania State University, University Park, PA, 168023504.

${ }^{c}$ Forest Biomass Innovation Center, Michigan State University, Escanaba, MI, 49829, USA

\section{*Corresponding author:}

Tel: 315.787 .2490

Fax: 315.787.2216

Email: 1bs33@cornell.edu

\begin{abstract}
Lignocellulosic bioenergy crops such as shrub willow (Salix spp.) are expected to have a significant role in climate mitigation strategies. Yield is perhaps the most important trait for genetic selection and development of biomass feedstocks, but the selection process is complicated by the strong influence that environmental factors has on cultivar performance. Understanding the genotype-by-environment interactions using regional yield trials of shrub willow will inform future breeding efforts and improve the ability to make regionally-specific cultivar recommendations. We analyzed two yield trial datasets containing genotypes from
\end{abstract}


successive rounds of breeding using a series of mixed models. Stability variance parameters were used together with overall yields to identify genotypes with stable yields or specific adaptation. Analysis of the first dataset revealed a group of triploid interspecific hybrid cultivars with exceptional performance and specific adaptation to either poor or good quality environments. The best performing cultivar showed a $14 \%$ yield improvement over the mean of the check cultivars. In the second dataset, new selections were assessed along with the top performing cultivars from dataset 1 . New triploid hybrids had yields 19 to $27 \%$ greater than the check cultivar and exhibited similar patterns of specific adaptation as some of the selections from the first dataset. Partial least squares regression analysis indicated that top-yielding genotypes were favored in environments with higher temperatures and greater growing degree days. This analysis demonstrates incremental improvements in yield with successive rounds of breeding through the development of interspecific triploid hybrids.

Key words: AMMI, biomass, Eberhart-Russell, Finlay-Wilkinson, Salix, short rotation coppice 


\section{Introduction}

Increasing energy production from renewable, low-carbon sources is an imperative for mitigating the impacts of climate change. Current US national energy policy mandates a rapid expansion of cellulosic biofuel production over the coming years (Environmental Protection Agency 2007). These statutory provisions will likely only be met by increasing the area devoted to growing dedicated bioenergy crops, especially on low productivity agricultural lands. Perennial lignocellulosic feedstocks such as shrub willow (Salix spp.) and poplar (Populus spp.) managed in short rotation coppice systems are expected to provide a substantial portion of biomass needed in the US to achieve renewable energy goals (U. S. Department of Energy 2011). These crops remain on the landscape for many years, so selecting cultivars that are not well matched to local climatic and edaphic conditions can be a costly mistake to commercial growers.

Shrub willow is a fast-growing, woody perennial $\mathrm{C}_{3}$ feedstock that is well adapted to humid, temperate regions such as the northeastern and upper midwestern US. It is typically managed on 2-4 year harvest cycles with an expected productive crop life of over 25 years. In addition to supplying large amounts of biomass over short periods of time, shrub willow has low or net negative greenhouse gas emissions (Caputo et al. 2014; Djomo et al. 2015; Wightman et al. 2015), mainly through high rates of C storage in belowground components (Cunniff et al. 2015; Pacaldo et al. 2013; 2014), and has greenhouse gas mitigation potential when converted to bioenergy for displacement of fossil fuel (Djomo et al. 2011). Other features that make shrub willow interesting for breeding are that it is dioecious, is amenable to interspecific hybridization, has multiple ploidy levels, and can be clonally propagated. Shrub willow re-sprouts vigorously after harvest. has a low nutrient demand and high nutrient use efficiency (Aronsson et al. 2014; 
Hangs et al. 2014) and a large potential for applications in phytoremediation projects (Kuzovkina and Quigley 2005).

In the US, commercial production of shrub willow for use in biopower production was recently initiated on a small scale in New York State, in part due to a regionally specific federal assistance program (Volk et al. 2016). In Canada, despite decades of research into the production potential of shrub willow, particularly of native species, wide-spread adoption has been hampered by socio-economic issues (Larocque et al. 2013; McKenney et al. 2014). Current economic analyses of short-rotation biomass production including willow suggest that yield is an important factor determining economic viability (Buchholz and Volk 2011; Hauk et al. 2014). Recent breeding efforts in the US have focused largely on improving yields by capturing heterosis from novel interspecific crosses (Smart and Cameron 2012; Smart et al. 2005). Specifically, crosses between diploid and tetraploid species producing triploid progeny have demonstrated substantial yield gains over commercial check cultivars in early stages of evaluation (Serapiglia et al. 2014).

Yield data on short rotation woody crop production in North America is somewhat limited, due largely to its relatively recent reemergence on the continent as a biomass feedstock (Volk et al. 2006). However, recent initiatives aimed at testing newly bred cultivars in regional yield trials have generated valuable datasets for testing genotype-by-environment interactions (GEI) in North America (Serapiglia et al. 2014; Volk et al. 2011). Traditional analysis of variance (ANOVA) approaches to multi-environment datasets have demonstrated significant GEI in shrub willow (Larsen et al. 2014; Mosseler et al. 2014; Serapiglia et al. 2013). However, these approaches often only test for the presence or absence of statistically significant interactions and thus do little to describe potential structure in the interaction, through which 
genotype stability or adaptability can be observed. Understanding these nuances is of great importance to breeding programs. Popular approaches to exploring yield stability include regression on environment mean techniques (Eberhart and Russel 1966; Finlay and Wilkinson 1963) or partitioning the total GEI variance among individual contributions from each genotype (Shukla 1972). While the regression approach is intuitive, it is often criticized for capturing two little of the GEI variance (Crossa 1990). Gollob (1968) suggested combining ANOVA with factor analytic decomposition of the interaction matrix in order to reduce noise and find structure among the interacting factors. Gauch (1988) popularized this approach for crop yield trial data with the so-called Additive Main Effects and Multiplicative Interactions (AMMI) model. The AMMI model is a powerful technique for interaction noise reduction, resulting in the assignment of interaction scores to each genotypes which are accurate measures of yield stability or adaptability. In a recent analysis of shrub willow yield trials across North America, Fabio et al. (2016) used the AMMI model to confirm the superior performance of a group of triploid hybrids, which were identified as having greater yields and exhibiting differential patterns of broad and narrow adaptability. That evaluation was restricted, however, to 16 genotypes present in 10 environments. This restriction was imposed in order to satisfy the need of a balanced dataset when using fixed-effects AMMI.

More recent efforts have demonstrated the utility of mixed effects models for the analysis of GEI datasets because they offer a flexible framework for exploring the GEI, specifically through the application of different variance-covariance structures, which impose certain assumptions about the complexity of the random factor variances (Hu and Spilke 2011; Sixto et al. 2014). The mixed model approach can handle unbalanced datasets, which are common in 
yield trial evaluations and can also incorporate heterogeneity of variances at multiple levels (Piepho et al. 2003; Smith et al. 2005; Raman et al. 2011).

In this study we present first rotation data from two sets of yield trials representing early and more recent stages of genetic improvement in shrub willow. Because not all genotypes evaluated were present in every test environment, the mixed model approach allowed us to incorporate a much greater number of observations available in the datasets than would otherwise allow in a fixed-effects framework. The objectives were 1) to test a series of mixed models on an existing dataset of shrub willow yields (Dataset 1) to identify stable and regionally adapted cultivars, 2) to analyze a new dataset (Dataset 2) of improved genotypes to identify yield improvements after successive breeding and selection and 3) to use environmental covariates to explain patterns in genotypic sensitivities to growing conditions in both datasets.

\section{Materials and methods}

\subsection{Yield Trial Dataset 1}

Breeding material consisted of native and naturalized accessions of Salix eriocephala and S. purpurea, collected from the northeastern US and eastern Canada, in combination with germplasm secured from the University of Toronto, consisting mainly of improved $S$. eriocephala and natural collections of S. miyabeana, native to East Asia, as well as S. viminalis, a native of Europe. Controlled intraspecific and interspecific crosses were performed at the State University of New York College of Environmental Science and Forestry, mostly in 1998 and 1999. Progeny from each successful cross were planted in nursery beds and individuals were selected based on growth traits for evaluation in a replicated selection field trial in Tully, New York in 2002 (Smart et al. 2008). Top-performing genotypes across multiple pedigrees were 
advanced to multi-location yield trials (Table 1). These yield trials were established between 2005 and 2011 and were hosted by eight institutions across six US states and two Canadian Provinces (Table 2). For detailed descriptions of trial establishment and design see Serapiglia et al. (2013) and Fabio et al. (2016). Planting material for each trial originated as 25-cm dormant, hardwood cuttings sourced from nursery beds at the SUNY-ESF Genetics Field Station in Tully, NY. After conventional site preparation, cuttings were planted by hand, usually in May or June, in a double-row configuration at a planting density of approximately 14,400 plants $^{-1}{ }^{-1}$. The distance between plants within a row was $0.61 \mathrm{~m}$, between adjacent rows $0.76 \mathrm{~m}$, and between double rows $1.52 \mathrm{~m}$ (alleys). Experimental units consisted of plots planted with a single cultivar, three double rows wide and 13 plants long. The outer two double rows were considered guard rows and only the middle double row was used for measurements in order to avoid edge effects. Each trial was planted with between 18 and 30 genotypes in a randomized complete block design, with four replicates of each genotype. Three check cultivars, 'SV1', 'SX61' and 'SX64' were used throughout testing and at least two checks were present in each trial.

After the first year of growth all aboveground biomass was cutback during dormancy close to ground level to promote a multi-stem coppice regrowth response in the following spring. At that time most trials received a single application of $112 \mathrm{~kg} \mathrm{~N} \mathrm{ha}^{-1}$ applied as ammonium sulfate. None of the Michigan trials and the trial in Saskatchewan received fertilizer during the study period. Trials were allowed to grow for three years after cutback, at which time 18-22 plants from the middle double row of each plot were harvested. Harvests were performed either manually by cutting whole stems at ground level with a brush saw and weighed with spring scales, or mechanically in a single-pass cut and chip operation using a forage harvester fitted with a specialized cutting header, where the chips were blown into a weigh bin with load cells. A 
subsample of whole or chipped stems from each plot were weighed fresh, oven dried at $65^{\circ} \mathrm{C}$ to a constant mass, then weighed again in order to calculate moisture content. Moisture content was used to express all plot weights as oven-dried Mg of biomass per ha per year. Prior to harvest, survival was scored on all harvested plants within a plot and any plot with $<65 \%$ survival excluded from analysis. This left 1,063 yield observations out of a possible 1,260. In total 21 genotypes were tested across 15 locations, with 35 (11\%) missing cells in the two-way genotypeby-environment table of means.

\subsection{Yield Trial Dataset 2}

A second round of cultivar testing was initiated in 2012 and 2013, based on topperforming genotypes from diverse pedigrees in a genetic selection trial established in 2008 at Cornell University in Geneva, NY (Serapiglia et al. 2014). Material tested was a combination of commercially available cultivars, many of which were present in Dataset 1, as well as improved genotypes whose pedigrees include commercial cultivars and accessions from the US and Europe

(Table 3). Trials were randomized complete block designs established in four locations:

Escanaba, MI, Fredonia, NY, Geneva, NY and Rock Springs, PA (Table 4). The Fredonia, NY location consisted of two side-by-side trials, one receiving $1,800 \mathrm{~kg} \mathrm{ha}^{-1}$ of lime and $84 \mathrm{~kg} \mathrm{~N}, \mathrm{P}$ and $\mathrm{K} \mathrm{ha}^{-1}$ in both the establishment year and first year post-coppice, and Geneva, NY received $160 \mathrm{~kg} \mathrm{~N}$ and $87 \mathrm{~kg} \mathrm{P} \mathrm{ha}^{-1}$ in the first year post-coppice, while Escanaba, MI and Rock Springs, PA received no soil amendments during the study period. For the purpose of GEI modeling in this study, the two trials in Fredonia, NY were considered as separate environments. Planting material was sourced from nursery beds at the New York State Agricultural Experiment Station (Geneva, NY) and from Double A Willow nursery (Fredonia, NY). Trials were established in a similar manner as those in Dataset 1 with a slightly modified double-row planting design, where 
plots contained 48 plants, 24 plants in the middle double row and outer double rows were split between adjacent plots consisting of a single 12-plant row of each genotype. One exception was at Geneva, NY, which was planted using two single rows per plot, 12 plants in length, and spaced 1.83 meters apart. Within row distances were adjusted to maintain the same plant density as the double row trials. Geneva and Fredonia, NY trials were harvested two years post-coppice, while Escanaba, MI and Rock Springs, PA were harvested three years post-coppice. At each harvest 16-20 plants were cut and chipped in a single pass and the chips were weighed, and a subsample was collected to determine moisture content. Dataset 2 consisted of 25 genotypes across 5 locations, and the check cultivar used was 'SX61'. The same 65\% plant survival per plot criterion as in Dataset 1 was applied so that Dataset 2 consisted of 448 out of a possible 500 observations. There were 114 out of 125 possible genotype-by-environment combinations, or $8 \%$ missing cells in the two-way table of means.

\subsection{Environmental Characterization}

Daily temperature and precipitation records were obtained from weather stations based on completeness of records and proximity to trial locations. Data from the National Oceanic and Atmospheric Agency, National Centers for Environmental Information (NOAA NCEI 2015) was used for all US trials and Canadian National Climate Data (Environment Canada 2015) for the two CA trials in Dataset 1. Daily solar radiation $\left(\mathrm{MJ} \mathrm{m}^{-2} \mathrm{~d}^{-1}\right)$ was obtained from the National Aeronautics and Space Administration's Prediction of Worldwide Energy Resource (NASA POWER 2015), given at a $1^{\circ}$ by $1^{\circ}$ grid scale. Soil samples at each location were generally collected at the time of planting, or occasionally soon after harvest. Some regional differences in soil sampling methods existed for Dataset 1. All soil samples obtained from trials in Dataset 2 were collected at the time of establishment and extractable nutrients were analyzed by Dairy One 
(Ithaca, NY) using the Morgan extraction method (Sims and Wolf 1995). Soil pH was assessed in a 1:1 soil/water ratio by weight and \% organic matter was determined by loss on ignition.

\subsection{Statistical Analysis}

Datasets 1 and 2 were analyzed separately using single-stage mixed model GEI analyses with PROC MIXED in SAS (SAS Institute Inc. 2013). Genotypes had undergone multiple rounds of selection and so were considered fixed effects. Environments were considered random effects, as was the effect of block, nested within environment. Because environment is considered random, interaction terms become random effects as well. The general form of the linear model fit to our yield datasets is shown in Eq. (1):

$$
Y_{i j k}=\mu+G_{i}+E_{j}+B_{k j}+(G E)_{i j}+\varepsilon_{i j k}
$$

where $Y_{i j k}$ is the yield observation for the $i$ th genotype in the $k$ th block for the $j$ th environment, $\mu$ is the overall mean, $G_{i}$ is the effect of the $i$ th genotype, $E_{j}$ is the effect of the $j$ th environment, $B_{k j}$ is the effect of the $k$ th block (replicate) in the $j$ th environment, $(G E)_{i j}$ is the interaction effect of the $i$ th genotype in the $j$ th environment, and $\varepsilon_{i j k}$ is the residual error term for the $i$ th genotype in the $k$ th block of the $j$ th environment.

We tested a series of mixed models which implement different variance-covariance structures in order to model random effects, with particular attention given to the genotypewithin-environment effects. A realistic situation for multi-trial data would be that each genotype in each environment has a unique variance estimate, and the modeled variance-covariance structure would be considered completely unstructured. However, with large datasets this type of structure is difficult to implement, since such a large number of variance parameters need to be estimated. Alternatively, simplified variance-covariance structures can be implemented that 
make certain assumptions about the degree of complexity associated with the random GEI effects and thus result in different numbers of parameters to be estimated. The resulting variance parameter estimates from these simplified structures are closely related to classical stability parameters, but in a mixed model formulation (Piepho 1999).

Each model is described below in terms their expectations (fixed effects) and variances (random effects). Each model contained two sources of error variance, block within environment $\left(\sigma_{b l k}^{2}\right)$ and residual error variance $\left(\sigma_{\varepsilon}^{2}\right)$, and for simplicity we have excluded these parameters from the descriptions of the models. All variance components were estimated using the REML procedure as implemented by default in SAS PROC MIXED.

(a) Simple additive model. Following Denis et al. (1997) this model assumes no interaction effects between the main effects of genotype and environment, and thus the $(G E)_{i j}$ term in Eq. (1) is dropped from the model. This model has a simple variance-covariance structure with the expectation and variance defined as

$$
E\left(Y_{i j}\right)=G_{i} ; \operatorname{Var}\left(Y_{i j}\right)=\sigma_{E}^{2}
$$

Where $\mathrm{Y}_{i j}$ is the yield of the $i$ th genotype in the $j$ th environment, and is defined by the fixed effect of genotype, $\mathrm{G}_{i}$. The variance is defined by one parameter, $\sigma_{E}^{2}$, which represents the random effect of environment. With this model it is assumed that there is no covariance between genotypes. Since most crop systems exhibit the presence of some GEI effects, this model represents an unlikely scenario, but it can be used as a baseline for interpreting the importance of GEI effects in subsequent models with higher degrees of complexity in modeling the interaction.

(b) Compound symmetry model. This model is synonymous with a standard two-way ANOVA with interaction, assuming constant variances for random effects. In this model there 
are two main diagonal elements of variance-covariance matrix that all genotypes share, the environment main effect, $\sigma_{E}^{2}$, and the interaction effect, $\sigma_{G E}^{2}$, as well as a common covariance in the off-diagonals, $\sigma_{G E}^{2}(\mathrm{Hu} 2014)$. This model is defined as

$$
E\left(Y_{i j}\right)=G_{i} ; \operatorname{Var}\left(Y_{i j}\right)=\sigma_{E}^{2}+\sigma_{G E}^{2}
$$

This model assumes that there is no difference in genotypic stability variance parameters, and has just two variance components to estimate.

(c) Heterogeneous compound symmetry model. This is a form of the compound symmetry model that attempts to model GEI by allowing for unique genotype-within-environment variances, $\sigma_{G E i}^{2}$. The covariance between two genotypes is defined by $\sigma_{G E l} \sigma_{G E 2} \rho$, which is the product of the square roots of two specific variances and a common correlation coefficient, $\rho$, whose value is less than one (Raman et al. 2011). The number of parameters to be estimated becomes $I+1$, representing the $I$ number genotypes tested plus the common correlation coefficient.

(d) Shukla's stability variance model. This represents a mixed model version of the classic stability analysis proposed by Shukla (1972). It is a generalized extension of

$$
E\left(Y_{i j}\right)=G_{i} ; \operatorname{Var}\left(Y_{i j}\right)=\sigma_{E}^{2}+\sigma_{G E i}^{2}
$$

Here each genotype is modeled as having a specific interaction variance, $\sigma^{2}{ }_{G E i}$. The interpretation of these genotype-specific variances is that smaller variances equate to more stable yields for a given genotype across test environments. A banded main diagonal variance-covariance structure is implemented in this model by specifying the 'type = UN' option in the random statement $(\mathrm{Hu}$ and Spilke 2011); however, in our case, there were problems with convergence, so the effect of genotype was added to the GROUP = statement in SAS PROC MIXED and the PARMS 
statement was used to initiate starting values at one for all variance components (Piepho 1999). This model has $I+1$ parameters to be estimated.

(e) Finlay-Wilkinson regression model. This is another mixed model version of a classic stability analysis (Finlay and Wilkinson 1963), where the genotype-specific interaction parameter is modeled as a regression on the environmental mean in the original fixed effects case. The mixed model version of this analysis can be implemented using a factor analytic (FA) variance-covariance structure (Piepho 1997; 1999). The interaction in Eq. (1) is modeled as a series of multiplicative terms:

$$
\sigma_{G E i}^{2}=\sum_{m=1}^{M} \lambda_{i m} \omega_{j m}+\delta_{i j}
$$

where $\lambda_{i}$ represents genotype factor loadings on a latent environmental variable, $\omega_{j}$, and the residual term $\delta_{i j}$ contains the unexplained interaction. The number of possible multiplicative terms is equal to one minus the number of genotypes or environments, whichever is least. In practice, since the first few factors explain the most variation, a more parsimonious model with one or two factors is considered adequate for explaining the interaction, and the remaining variability is pooled in the residual. In the mixed model Finlay-Wilkinson (F-W) analysis using the FA1(1) variance-covariance structure, no environment main effect is fitted. The multiplicative term is overparameterized, so the identifiability constraint that $\sigma^{2}{ }_{\omega}=1$ is implemented (Piepho 1999). Interpretation of $\lambda_{i}{ }^{\prime}$ s in terms of genotype stability or adaptability to environmental conditions is that a genotype with an average $\lambda_{i}$ would be considered stable. A genotype with a relatively large $\lambda_{i}$ would be well adapted to high-yielding environments with favorable growing conditions (i.e. high overall mean yields), where as a genotype with relatively a small $\lambda_{i}$ could be considered well adapted to low-yielding environments (Piepho 1998). This 
model has $I+1$ number of variance parameters, including a common residual variance, $\sigma_{\delta}^{2}$, associated with the FA1(1) structure.

(f) Eberhart-Russell regression model. This is a mixed model type of the EberhartRussell (E-R) fixed-effects model (Eberhart and Russell 1966), and is a nested case of the Finlay-Wilkinson model. The variance-covariance structure implemented for the E-R model is the FA(1) type, which allows for heterogeneity in interaction variance (Sixto et al. 2014). Therefore a genotype-specific deviation variance, $\sigma_{\delta i}^{2}$, is assigned to each genotype along with a specific loading score, $\lambda_{i}$. The values of $\lambda_{i}$ are interpreted in the same way as for the F-W model, but the deviation from regression variance component is an added measure of stability much like that of Shukla's model. The number of GEI parameters that need to be estimated becomes $2 I$.

\section{(g) Additive Main Effects and Multiplicative Interactions (AMMI) model. The AMMI} model was popularized by Gauch (1988), and is in a similar class of models as F-W and E-R in that the interaction is modeled by a set of multiplicative factors. Here the interaction is modeled with the same factor analytic structure as the F-W model, FA1 $(n)$, where $\mathrm{n}$ is the number of factors included in the model . Similar to the fixed-effects version we refer here to AMMI models according to the number of multiplicative parameters included, such that AMMI-1 includes one multiplicative factor (FA1(1)), and AMMI-2 includes two factors (FA1(2)). In addition to inclusion of $n>1$ factors, AMMI differs from F-W and E-R models in that the random main effect of environment is included in in the model. As with the F-W and E-R models, the $\lambda_{i, n}$ 's for each genotype can be interpreted as different sensitivities to environmental conditions. The number of variance parameters estimated are $I \times n+2$, including the main effect of environment and a residual term from the FA1 structure. For our datasets we had convergence issues implementing the FA1 $(n)$ structure, and so we used the "scoring $=n$ " option in the PROC 
MIXED statement which switches from the default Newton-Raphson to the Fisher scoring method for maximum likelihood estimation (Piepho 1999).

Finally, for each of the models outlined above, we also considered separate cases of heterogeneous residual error variance. The common, pooled homogeneous error estimate is therefore replaced by a separate estimate for each environment, $\sigma^{2}{ }_{R E S j}$. Heterogeneous error variances among environments is probably a more realistic scenario given the variable nature of multi-environment trial data (Raman et al. 2011) and given our unbalanced dataset.

Fit statistics including the residual log likelihood (-2 Res LL) and the Akaike information criterion (AIC) were used to select models with the best fit within datasets. Both fit statistics are of the smaller is better type, but the AIC imposes a penalty for number of parameters, given as -2 ResLL $+2 p$, where $p$ is the number of variance parameters estimated in the model. Log likelihood ratio tests were also calculated to assess the model fit improvement for homogeneous vs. heterogeneous residual error variances.

\subsection{Interaction Biplots}

Biplots display two different types of data in a combined graphic and have become very useful for interpreting GEI visually. In the case of AMMI models, scores from the first multiplicative factor can be combined with estimates of the main effects to construct so-called AMMI-1 biplots, or scores from the first two multiplicative factors can be combined for AMMI-2 biplots. In order to produce estimates of genotype and environment interaction scores for our unbalanced datasets, following Kumar et al. (2012), we first generated the Best Linear Unbiased Predictors (BLUPs) for the AMMI models with the FA1 $(n)$ variance-covariance structures. The BLUPs were then transferred into a now complete table of genotype-by-environment estimates, which 
was first environment centered, and then subjected to singular-value decomposition using PROC ILM in SAS.

\subsection{Partial Least Squares Regression}

To evaluate GEI in the context of environmental covariates collected for each trial location, we performed partial least squares (PLS) regression using PROC PLS in SAS. In similar fashion to the AMMI biplot construction, since the datasets were unbalanced, we first generated BLUPs to form a complete two-way table of GEI estimates. The compound symmetry variance-covariance model was used to generate BLUPs for both datasets separately. These estimates were subjected to a main-effects ANOVA to produce a table of residuals which contain the GEI effect. Since the PLS procedure is sensitive to scale, estimates were standardized to have a mean of zero and variance of one prior to analysis following Crossa et al. (2015). Biplots were constructed using the first and second PLS factors to illustrate relationships between environment scores and genotype and covariate loadings.

\section{Results}

\subsection{Yield Trial Dataset 1}

The mixed model analyses of Dataset 1 with 21 genotypes and 15 environments indicated that models with larger numbers of variance parameters tended to provide the best fit (Table 5). For homogeneous residual error variance scenarios, the AMMI-2 and E-R models provided the best fit to the data based on residual log likelihood. Based on AIC, which imposes a penalty for the number of parameters estimated, AMMI-1 and AMMI-2 models had the best fit. This is interesting since the AMMI-2 model had the most parameters to be estimated, with one additional parameter compared to the E-R model. Also, for the E-R model, five genotype- 
specific residual variances were estimated as zero, which as a result do not contribute to the penalty for the number of model parameters in the calculation of the AIC value.

In every case when residual error variances were considered to be heterogeneous for environments, model fit improved significantly $(P<0.0001)$ over the homogeneous models based on the residual log likelihood ratio Chi-squared tests (Table 5). Among these scenarios, the E-R and AMMI-2 models provided the best fit to Dataset 1. Although the AIC for the E-R model was lower than for AMMI-2, nine genotype-specific residual variances $\left(\boldsymbol{\sigma}_{\mathbf{i}}{ }_{\mathrm{i}}\right)$ were estimated at zero, and consequently were not included in the AIC calculation.

The E-R and AMMI-2 models with heterogeneous residual error variances were selected to represent genotype least squared mean yields and stability parameters (Table 6). Genotype yield rankings between the two models were very similar (Spearman's $r=0.98$ ). According to the E-R model, 'Fabius' had the greatest overall yield and an above average regression coefficient, suggesting that it was better adapted to high-yielding environments. Cultivars with above average yields and below average regression coefficients were 'Oneonta' and 'Tully Champion', and could be thought of as better adapted to low-yielding environments. 'SX64' and 'Marcy' had above average yields and regression coefficients close to the mean, suggesting that they had relatively stable yields. Since nine out of the 21 genotype-specific residual variances were estimated to be zero according to the E-R model, it could be assumed that the FA(1) structure fit the data well for these genotypes, and they could be considered to be stable. While most of the genotypes with zero residual variances in the E-R model were below average in yield, 'Marcy', 'Fabius' and 'Oneonta' had combined high mean yields and zero or small genotype-specific residual variances. 'Tully Champion' had the second greatest specific residual 
variance, while 'SV1' had the greatest, suggesting a poor fit to the factor analytic variancecovariance structure.

For the AMMI-2 model 'Fabius', 'Oneonta' and 'SX64' were again among the top yielding genotypes (Table 6 ). The $\lambda_{i}$ 's for the first factor of the AMMI-2 model were highly correlated with the E-R model regression coefficients (Pearson's $r=0.93, P<0.0001$ ). A biplot based on the BLUPs from the AMMI-2 model allows visualizing the genotype and environment interaction (Fig. 1). Environments on the left side of the figure were among the highest yielding, and some of the top-performing genotypes group with these environments. The environments in the lower-right of the figure were the lowest yielding environments, and the lowest yielding genotype, 'S25' falls in the same region, as does 'Tully Champion', however its mean yield was relatively greater, suggesting again that it is well adapted to low-yielding environments. 'Oneida' and 'Millbrook' lie close to the origin, suggesting more stable yields across environments. The genotypes also group according to pedigree and ploidy level, with S. miyabeana (tetraploid) and S. viminalis $\times$ S. miyabeana (triploid) genotypes clustered on the left-hand side of the figure, and S. purpurea (diploid) and S. koriyanagi $\times$ S. purpurea (diploid) genotypes clustered mainly on the right. Of the three check cultivars, 'SV1', 'SX61' and 'SX64', the latter two are $S$. miyabeana tetraploids, and were shown to have above average yields and somewhat stable interaction variance parameters. However, 'SV1' (diploid) had a below average overall yield and large interaction variance parameters, suggesting it is a poor candidate for a check in future testing.

The partial least squares regression analysis for Dataset 1 reflected the broad geographic variability across trial locations (Fig. 2). The first factor showed a pattern of increasing temperatures and growing degree days at lower latitudes. Since growing season maximum 
temperature (Tmax), growing degree days (GDD) and annual minimum temperature (Tmin) are correlated with one another, these factors all group together on the right-hand side of the biplot. Tetraploid S. miyabeana genotypes such as 'Marcy', 'Cicero', 'Canastota' and 'SX64'together with the top-yielding $S$. viminalis $\times S$. miyabeana triploid hybrid, 'Fabius', grouped with these temperature-related variables, suggesting better performance in warmer environments. In contrast, 'Tully Champion', also a $S$. viminalis $\times S$. miyabeana triploid grouped with the variable latitude (LAT) with was on the opposite end of the projection of factor 1, suggesting this cultivar performed better in cooler environments. Factor two seemed to be associated with increasing precipitation and decreasing solar radiation along a longitudinal gradient. The $S$. viminalis $\times S$. miyabeana cultivar 'Otisco' and the S. purpurea 'Fish Creek' had strong, but opposite loadings along the second PLS factor. However, it should be noted that in this analysis only about $25 \%$ of the overall variation in interactions could be explained by the first two PLS factors.

\subsection{Yield Trial Dataset 2}

The same mixed modeling approach described above was used to analyze 25 genotypes planted in five environments, consisting of new selections and some commercial cultivars also present in Dataset 1 (Table 7). The AMMI-2 and E-R models again provided the best model fit for the case of homogeneous error variance. Again, log likelihood ratio tests showed that heterogeneous error variance provided a better fit in all cases. Based on -2 Res LL, AMMI-2 and E-R models were the best models, and based on AIC, AMMI-2 and AMMI-1 models had the best fits, despite AMMI-2 having the greatest number of model parameters to be estimated. There were some contrasting differences for variance parameters between AMMI-1 and AMMI2 models (Table 7). Most notably, the main effect of environment was estimated at zero for the AMMI-2 model, as was the common residual variance, $\sigma_{\beta}^{2}$, present in the FA1 variance- 
covariance structure. This is likely due to the relatively low number of testing environments. In light of this, the more parsimonious AMMI-1 model is likely a better fit for Dataset 2.

A mixed model version of an AMMI-1 biplot was constructed using the first factor scores and model yield estimates for genotypes (Fig. 3). Four genotypes, LA970253, 'Preble', 'Tonawanda' and 'Victor' produced greater or similar yields compared to 'Fabius' and 'Tully Champion', which were identified as having high yields and specific adaptability in Dataset 1. LA970253 and 'Preble' are $S$. viminalis $\times$ S. miyabeana triploids, whereas 'Tonawanda' is a $(S$. koriyanagi $\times S$. purpurea) $\times S$. miyabeana triploid, and 'Victor' is a $S$. purpurea $\times S$. miyabeana triploid. These four new cultivars had greater than average factor 1 scores and the linear nature of the relationship between yield and factor 1 scores suggests that these genotypes are well adapted to higher quality environments. In addition to those top-performing genotypes, an additional five previously untested genotypes had mean yields greater than the check cultivar, 'SX61' and near average interaction scores (Fig. 3). Cultivars 'India' and 'Dimitrios' are from Canadian and Swedish breeding programs, respectively, and performed poorly in our trials. 'Dimitrios' was frequently observed to show signs of mammalian browsing and 'India' was highly susceptible to potato leafhopper (Empoasca fabae Harris), a known pest for some species of shrub willow. Three S. purpurea genotypes, 05X-293-047, 94006 and 'Fish Creek' also grouped together with low yields and below average interaction variance parameters.

The PLS analysis for Dataset 2 indicated differences across a latitudinal gradient, with the southernmost location, Rock Springs, PA, being associated with higher temperatures, as well as greater growing season precipitation for factor 1 compared to the northernmost location, Escanaba, MI, which was also associated with higher soil pH and phosphorus levels (Fig. 4). A number of the $S$. viminalis $\times S$. miyabeana triploids grouped on the right-hand side of the figure 
indicating a positive association with higher temperatures. Factor 2 seemed to be associated with differences in soil potassium levels between Geneva and the Fredonia Amended trials. The Fredonia Amended trial had the highest potassium levels, and all of the S. purpurea genotypes grouped with that trial, suggesting a positive response to greater soil fertility for that species.

\section{Discussion}

In our analysis we have demonstrated that breeding efforts have made substantial gains in yield over the foundational material, which served as checks in these newer evaluations. In a previous fixed effects AMMI analysis of a smaller dataset (Fabio et al 2016), 'Fabius' and 'Tully Champion' were found to be top-performing cultivars in contrasting high and low-yielding environments, respectively (Fabio et al. 2016). The present expanded mixed model analysis was conducted over a larger number of environments and included a larger number of cultivars, and we confirmed the superior performance of 'Fabius', with a $14 \%$ increase in overall yield compared to the mean of the check cultivars. 'Tully Champion', however, showed a yield advantage in the environments with the lowest overall yields, suggesting specific adaptation. Our expanded analysis also highlighted other promising cultivars from other pedigrees, such as 'Oneonta', a S. purpurea $\times$ S. miyabeana triploid, and 'Marcy', an improved S. miyabeana tetraploid, thus diversifying the array of commercially available cultivars.

Genotype-by-environment interactions in shrub willow have been noted in European studies (Larsen et al. 2014; Rönnberg-Wästljung and Thorsén 1988). However, until recently, data on cultivar performance from multiple shrub willow yield trials was limited for North America, largely due to the longer generation times and production cycles for this perennial crop. In some early work on cultivar evaluations, Kiernan et al. (2003) tested foundational germplasm 
prior to any US breeding improvements and found that 'SX61' and 'SX64' exhibited both high and stable yields.

Dataset 2 provided an opportunity to test new breeding material against cultivars identified in Dataset 1 as high-yielding and specifically adapted to both low and high quality environments. Again, incorporating heterogeneous error variances significantly improved model fit. AMMI models provided the best fit, but a number of variance estimates were estimated at zero for the AMMI-2 model, including the main effect of environment, suggesting this model was not well suited for this smaller dataset containing only five environments. We selected the more parsimonious AMMI-1 as the best representation of Dataset 2, but it should be recognized that standard errors of interaction variance estimates were still rather large for this dataset (Table 6). Patterns in yield and adaptability exhibited by 'Fabius' and 'Tully Champion' in Dataset 2 were similar to those of Dataset 1, in that both cultivars maintained high yields, but had contrasting interaction variances. In Dataset 2, a new group of genotypes emerged as promising, including two S. viminalis $\times$ S. miyabeana triploids, LA970253 and 'Preble'. These two new selections are of the same diversity group as 'Fabius' and 'Tully Champion' and had on average $4.2 \%$ greater yields over those cultivars and $26 \%$ greater yields over the commercial check, 'SX61'. Triploids 'Tonawanda' ((S. koriyanagi $\times$ S. purpurea $) \times$ S. miyabeana $)$ and 'Victor' $(S$. purpurea $\times$ S. miyabeana) had on average a $14.6 \%$ yield advantage over the check within the same diversity, 'Millbrook', and a $21.1 \%$ increase over 'SX61'. Within the S. purpurea diversity group, we did not observe new genotypes with yield increases over the commercial cultivar 'Fish Creek'. However one genotype, 01X-265-019 $($ S. koriyanagi $\times$ S. purpurea $)$ had an equivalent mean yield compared to 'Fish Creek', whereas in Dataset 1, other S. koriyanagi $\times$ S. purpurea genotypes had mean yields $16.9 \%$ lower than 'Fish Creek'. 
The breeding history of shrub willow as a dedicated bioenergy crop in North America is brief, but employing a strategy of developing interspecific hybrids displaying heterosis has shown potential for improving yields in early selection trials for this emerging crop (Serapiglia et al. 2014). These interspecific hybrids have simultaneously allowed for substantial yield gains and integrated resistance to pests and diseases. Improved S. viminalis and associated interspecific hybrids in Europe has led to greater yields (Aylott et al. 2008; Larsen et al. 2014; Lindegaard et al. 2011); however, it was recognized early on that S. viminalis cultivars in the US were highly susceptible to potato leafhopper (Labrecque and Teodorescu 2005; Smart and Cameron 2008). In the US breeding program, hybridization of $S$. viminalis with $S$. miyabeana has produced some of the greatest gains in yield, as demonstrated by 'Fabius' and 'Tully Champion' in Dataset 1. These two cultivars are siblings, but interestingly have been shown to have varying degrees of susceptibility to potato leafhopper (Gouker and Smart 2015). In our analysis of Dataset 2 'Preble', a cross between the same $S$. viminalis mother and an improved S. miyabeana, was shown to outperform 'Fabius' and 'Tully Champion'.

In further support of yield improvements through interspecific hybridization, new triploid selections such as 'Tonawanda' $((S$. koriyanagi $\times S$. purpurea $) \times S$. miyabeana $)$ and 'Victor' $(S$. purpurea $\times S$. miyabeana) outperformed both improved $S$. purpurea and $S$. miyabeana cultivars, and performed similarly to 'Fabius' and 'Tully Champion'. These genotypes have not demonstrated susceptibility to common willow pests, and perhaps more importantly they appear to be more resistant to leaf rust (Melampsora spp), which can be damaging to pure S. purpurea. Since pest and disease populations can evolve rapidly, deployment of diverse cultivars in future commercial plantings will likely provide a safeguard against potential pest and disease outbreaks. For instance, research in the UK has shown that planting polycultures of diverse 
cultivars can maintain greater yields over monocultures of Salix spp. under pressure from rust (McCracken and Dawson 2003; McCracken et al. 2011).

In a similar mixed model analysis of numerous interspecific poplar (Populus) hybrids grown in Spain for biomass production, Sixto et al. (2014) also found evidence of differences in genotypic adaptations among different taxonomic groups. They argue that adaptive patterns may have been influenced by the geographic origin (i.e. Europe or North America) of the parental species and that hybrids involving the European native $P$. nigra may possess specific adaptation to the Mediterranean climate. In our analysis we did not find evidence supporting the notion that native species or hybrids involving natives are better adapted when grown in North America. Salix eriocephala is a native species of North America and cultivar 'S25' in Dataset 1 was the lowest yielding cultivar overall. Interspecific hybridization involving S. eriocephala has proven to be difficult (Kopp et al. 2001), and intraspecific breeding has not been shown to improve rust resistance in $F_{1}$ progeny (Cameron et al. 2008). S. purpurea is a naturalized species of North America, and both natural accessions and improved cultivars showed poor performance in general across both of our datasets. Both S. eriocephala and S. purpurea are susceptible to leaf rust, which may have contributed to lower yields. Current efforts are underway to characterize the pathogen-host relationship between rust and S. purpurea and to evaluate novel interspecific $F_{1}$ families for improved rust resistance.

Sixto et al. (2014) also speculated that a three-way hybrid involving $P$. nigra performed worse than the two-way hybrid, which the authors attribute to a possible reduction in the genetic contribution of $P$. nigra to biomass traits in the three-way cross, leading to poorer performance. In our Dataset 2, we tested three three-way hybrids, 05X-326-010, 05X-326-015 and 'Dimitrios', which involved a $S$. viminalis $\times$ S. schwerinii parent, and they all exhibited poor performance, 
with low mean yields and below average interaction variance parameters. The apparent superior biomass traits possessed by $S$. viminalis could have been diminished in a similar way in this complex cross, although in the case of 'Dimitrios', poor performance was likely due to increased pest pressure based on visual surveys in the field.

The use of partial least squares regression allowed us to test for relationships between GEI and environmental covariates. The geographic range among the test environments was relatively large, and latitudinal and longitudinal gradients were apparent, although only about $25 \%$ of the total variation in GEI response was explained by PLS in Dataset 1. Some of the topperforming cultivars such as 'Fabius' and 'Marcy' were positively associated with higher temperatures and greater growing degree days (Fig. 3). Sixto et al. (2016) used factorial regression and found differential responses of poplar hybrids to latitude and maximum temperatures during the growing season. For Dataset 2, the smaller number of environments covered a relatively smaller geographic range, but we were able to capture more than twice the variability in genotype response variables compared to Dataset 1 . We had more complete records for soil nutrient concentrations in Dataset 2 and some of the patterns revealed through PLS suggest some genotypic differences in response to particular nutrients, such as phosphorus and potassium, but further testing is needed in this area. Some of the new triploid hybrids in Dataset 2 were also positively associated with higher temperatures and growing degree days as they were in Dataset 1. A proposed production zone of shrub willow in the US was previously restricted to more northern latitudes (Walsh et al. 2003), but our results suggest that a southward expansion of this boundary should be tested, perhaps particularly in the case of the triploid hybrids. This could have implications for models that compare production potential of willow and $\mathrm{C}_{4}$ perennials like switchgrass (Panicum virgatum L.) and Miscanthus across large geographic and climatic regions. 
For a perennial crop like shrub willow, the term yield stability has an additional dimension in the sense that a single crop is proposed to have a productive life of over 25 years, or for at least seven three-year harvest cycles. While we have reported yield for only the first harvest cycle, Sleight et al. (2016) analyzed first and second rotation data from a subset of the yield trials in Dataset 1 and found a strong relationship in first rotation yields determining the relative change in yields of the second rotation. They proposed that poor establishment leads to low first rotation yields, but those poor performing trials tend to have the greatest relative increase in yield in the second rotation. A follow up analysis of data across three harvest cycles at two locations showed little change in rank among cultivar yields (Sleight and Volk 2016). A truly accurate assessment of shrub willow cultivar stability and adaptability will likely need to involve multiple rotations, and a mixed model framework as proposed earlier has (Piepho and Eckl 2014) and used here.

\section{Conclusion}

The use of mixed models has allowed us to analyze a large yet unbalanced dataset of shrub willow yields in order to characterize GEI. The main findings are incremental increases in yield were achieved through traditional breeding techniques, that interspecific triploid hybrids seem to express the largest yield gains, especially in warmer environments, and that the GEI allows for the identification of cultivars adapted to low and high-yielding environments. This is critical for deploying regionally adapted and high-yielding genotypes for stands expected to be productive over 20 years. As a result of this work we have identified a number of recently bred, high-yielding triploid hybrids from diverse pedigrees that will be advanced for commercialization. Recurrent selection of improved of diploid and tetraploid progeny for the development of new triploid hybrids will be a key focus of future breeding efforts. 


\section{Acknowledgements}

Funding for maintenance and data collection in the yield trials in Dataset 1 was provided by the North Central Regional Sun Grant Center at South Dakota State University through a grant from the US Department of Energy Bioenergy Technologies Office under Award number DE-FC36-05GO85041 and the US DOE Regional Feedstock Partnership. Cultivar testing from Dataset 2 was supported by a grant from USDA-National Institute of Food and Agriculture (NIFA) through the Northeast Sun Grant Initiative and by Agriculture and Food Research Initiative Competitive Grant No. 2012-68005-19703 from the USDA NIFA for the NEWBio Coordinated Agricultural Project. We are grateful to Steve Gordner and Curt Carter for excellent technical assistance, and Dr. Hans-Peter Piepho for guidance with the mixed model AMMI analysis. Dr. Mateo Vargas contributed code and advice for performing the PLS analysis. We thank Dennis Rak of Double A Willow for hosting and managing the Fredonia, NY trial.

\section{References}

Aronsson, P., Rosenqvist, H., Dimitriou, I., 2014. Impact of nitrogen fertilization to short-rotation willow coppice plantations grown in Sweden on yield and economy. Bioenerg. Res. 7, 993-1001.

Aylott, M.J., Casella, E., Tubby, I., Street, N.R., Smith, P., Taylor, G., 2008. Yield and spatial supply of bioenergy poplar and willow short-rotation coppice in the UK. New Phytol. 178, 358-370.

Buchholz, T., Volk, T.A., 2011. Improving the profitability of willow crops-identifying opportunities with a crop budget model. Bioenerg. Res. 4, 85-95.

Cameron, K.D., Phillips, I.S., Kopp, R.F., Volk, T.A., Maynard, C.A., Abrahamson, L.P., Smart, L.B., 2008. Quantitative genetics of traits indicative of biomass production and heterosis in 34 full-sib $\mathrm{F}_{1}$ Salix eriocephala families. Bioenerg. Res. 1, 80-90.

Caputo, J., Balogh, S.B., Volk, T.A., Johnson, L., Puettmann, M., Lippke, B., O'Neil, E., 2014. Incorporating uncertainty into a life cycle assessment (LCA) model of short-rotation willow biomass (Salix spp.) crops. Bioenerg. Res. 7, 48-59.

Crossa, J., 1990. Statistical analyses of multilocation trials. Adv. Agron. 44, 55-85.

Crossa, J., Vargas, M., Cossani, C.M., Alvarado, G., Burgueño, J., Mathews, K.L., Reynolds, M.P., 2015. Evaluation and interpretation of interactions. Agron. J. 107.

Cunniff, J., Purdy, S.J., Barraclough, T.J.P., Castle, M., Maddison, A.L., Jones, L.E., Shield, I.F., Gregory, A.S., Karp, A., 2015. High yielding biomass genotypes of willow (Salix spp.) show differences in below ground biomass allocation. Biomass Bioenerg. 80, 114-127.

Denis, J.B., Piepho, H.P., VanEeuwijk, F.A., 1997. Modelling expectation and variance for genotype by environment data. Heredity 79, 162-171. 
Djomo, S.N., Kasmioui, O.E., Ceulemans, R., 2011. Energy and greenhouse gas balance of bioenergy production from poplar and willow: a review. GCB Bioenergy 3, 181-197.

Djomo, S.N., Witters, N., Van Dael, M., Gabrielle, B., Ceulemans, R., 2015. Impact of feedstock, land use change, and soil organic carbon on energy and greenhouse gas performance of biomass cogeneration technologies. Appl. Energ. 154, 122-130.

Eberhart, S.A., Russell, W.A., 1966. Stability parameters for comparing varieties. Crop Sci. 6, 36-40.

Environment Canada, 2015. National Climate Data. http://climate.weather.gc.ca/. (accessed 16.05.16).

Environmental Protection Agency, 2007. Finalized regulations for a renewable fuel standard (RFS) program for 2007 and beyond. 72 Fed. Reg. 23900.

Fabio, E.S., Volk, T.A., Miller, R.O., Serapiglia, M.J., Gauch, H.G., Van Rees, K.C.J., Hangs, R.D., Amichev, B.Y., Kuzovkina, Y.A., Labrecque, M., Johnson, G.A., Ewy, R.G., Kling, G.J., Smart, L.B., 2016. Genotype $\times$ environment interaction analysis of North American shrub willow yield trials confirms superior performance of triploid hybrids. GCB Bioenergy. doi: $10.1111 /$ gcbb.12344.

Finlay, K.W., Wilkinson, G.N., 1963. The analysis of adaptation in a plant-breeding programme. Crop Pasture Sci. 14, 742-754.

Gauch, H.G., 1988. Model selection and validation for yield trials with interaction. Biometrics 44, 705715 .

Gollob, H.F., 1968. A statistical model which combines features of factor analytic and analysis of variance techniques. Psychometrika 33, 73-115.

Gouker, F.E., Smart, L.B., 2015. Genetic diversity of willow. Fact sheet. http://willow.cals.cornell.edu/. (accessed 17.8.16).

Hangs, R.D., Schoenau, J.J., Van Rees, K.C.J., Bélanger, N., Volk, T., Jensen, T., 2014. First rotation biomass production and nutrient cycling within short-rotation coppice willow plantations in Saskatchewan, Canada. Bioenerg. Res. 7, 1091-1111.

Hauk, S., Knoke, T., Wittkopf, S., 2014. Economic evaluation of short rotation coppice systems for energy from biomass-A review. Renew. Sust. Energ. Rev. 29, 435-448.

$\mathrm{Hu}, \mathrm{X}$.Y., 2014. Combined yield comparison and stability evaluation of rape genotypes using the mixed model. Field Crops Res. 167, 11-18.

Hu, X.Y., Spilke, J., 2011. Variance-covariance structure and its influence on variety assessment in regional crop trials. Field Crops Res. 120, 1-8.

Kiernan, B.D., Volk, T.A., Tharakan, P.J., Nowak, C.A., Phillipon, S.P., Abrahamson, L.P., White, E.H., 2003. Clone-site testing and selections for scale-up plantings, Final Report prepared for the United States Department of Energy. SUNY-ESF, Syracuse, NY, p. 67 pp.

Kopp, R.F., Smart, L.B., Maynard, C.A., Isebrands, J.G., Tuskan, G.A., Abrahamson, L.P., 2001. The development of improved willow clones for eastern North America. Forestry Chron. 77, 287-292.

Kumar, A., Verulkar, S.B., Mandal, N.P., Variar, M., Shukla, V.D., Dwivedi, J.L., Singh, B.N., Singh, O.N., Swain, P., Mall, A.K., Robin, S., Chandrababu, R., Jain, A., Haefele, S.M., Piepho, H.P., Raman, A., 2012. High-yielding, drought-tolerant, stable rice genotypes for the shallow rainfed lowland drought-prone ecosystem. Field Crops Res. 133, 37-47.

Kuzovkina, Y.A., Quigley, M.F., 2005. Willows beyond wetlands: Uses of Salix L. species for environmental projects. Water Air Soil Poll. 162, 183-204.

Labrecque, M., Teodorescu, T.I., 2005. Field performance and biomass production of 12 willow and poplar clones in short-rotation coppice in southern Quebec (Canada). Biomass Bioenerg. 29, 1-9.

Larocque, G.R., DesRochers, A., Larchevêque, M., Tremblay, F., Beaulieu, J., Mosseler, A., Major, J.E., Gaussiran, S., Thomas, B.R., Sidders, D., Périnet, P., Kort, J., Labrecque, M., Savoie, P., Masse, S., Bouman, O.T., Kamelchuk, D., Benomar, L., Mamashita, T., Gagné, P., 2013. Research on hybrid poplars and willow species for fast-growing tree plantations: Its importance for growth and yield, silviculture, policy-making and commercial applications. Forestry Chron. 89, 32-41.

Larsen, S.U., Jørgensen, U., Lærke, P.E., 2014. Willow yield is highly dependent on clone and site. Bioenerg. Res. 7, 1280-1292. 
Lindegaard, K.N., Carter, M.M., McCracken, A., Shield, I.F., MacAlpine, W., Jones, M.H., Valentine, J., Larsson, S., 2011. Comparative trials of elite Swedish and UK biomass willow varieties 20012010. Asp. Appl. Biol. 112, 57-66.

McCracken, A.R., Dawson, W.M., 2003. Rust disease (Melampsora epitea) of willow (Salix spp.) grown as short rotation coppice (SRC) in inter- and intra-species mixtures. Ann. Appl. Biol. 143, 381393.

McCracken, A.R., Walsh, L., Moore, P.J., Lynch, M., Cowan, P., Dawson, M., Watson, S., 2011. Yield of willow (Salix spp.) grown in short rotation coppice mixtures in a long-term trial. Ann. Appl. Biol. 159, 229-243.

McKenney, D.W., Weersink, A., Allen, D., Yemshanov, D., Boyland, M., 2014. Enhancing the adoption of short rotation woody crops for bioenergy production. Biomass Bioenerg. 64, 363-366.

Mosseler, A., Major, J.E., Labrecque, M., 2014. Genetic by environment interactions of two North American Salix species assessed for coppice yield and components of growth on three sites of varying quality. Trees $28,1401-1411$.

NASA POWER, 2015. Prediction of worldwide energy resource climatology resource for agroclimatology. http://power.larc.nasa.gov/. (accessed 16.05.16).

NOAA NCEI, 2015. Global historical climatology network. http://www.ncdc.noaa.gov/data-access. (accessed 16.05.16).

Pacaldo, R., Volk, T., Briggs, R., 2013. Greenhouse gas potentials of shrub willow biomass crops based on below- and aboveground biomass inventory along a 19-year chronosequence. Bioenerg. Res. $6,252-262$.

Pacaldo, R., Volk, T., Briggs, R., 2014. Carbon sequestration in fine roots and foliage biomass offsets soil $\mathrm{CO}_{2}$ effluxes along a 19-year chronosequence of shrub willow (Salix x dasyclados) biomass crops. Bioenerg. Res. 7, 769-776.

Piepho, H.P., 1997. Analyzing genotype-environment data by mixed models with multiplicative terms. Biometrics 53, 761-766.

Piepho, H.P., 1998. Methods for comparing the yield stability of cropping systems. J. Agron. Crop Sci. 180, 193-213.

Piepho, H.P., 1999. Stability analysis using the SAS system. Agron. J. 91, 154-160.

Piepho, H.P., Büchse, A., Emrich, K., 2003. A hitchhiker's guide to mixed models for randomized experiments. J. Agron. Crop Sci. 189, 310-322.

Piepho, H.P., Eckl, T., 2014. Analysis of series of variety trials with perennial crops. Grass Forage Sci. 69, 431-440.

Raman, A., Ladha, J.K., Kumar, V., Sharma, S., Piepho, H.P., 2011. Stability analysis of farmer participatory trials for conservation agriculture using mixed models. Field Crops Res. 121, 450459.

Rönnberg-Wästljung, A., Thorsén, J., 1988. Inter- and intraspecific variation and genotype $\times$ site interaction in Salix alba L., S. dasyclados Wimm. and S. viminalis L. Scand. J. For. Res. 3, 449463.

SAS Institute Inc., 2013. 9.4 ed. SAS Institute, Inc, Cary, NC, USA.

Serapiglia, M.J., Cameron, K.D., Stipanovic, A.J., Abrahamson, L.P., Volk, T.A., Smart, L.B., 2013. Yield and woody biomass traits of novel shrub willow hybrids at two contrasting sites. Bioenerg. Res. 6, 533-546.

Serapiglia, M.J., Gouker, F.E., Hart, J.F., Unda, F., Mansfield, S.D., Stipanovic, A.J., Smart, L.B., 2015. Ploidy level affects important biomass traits of novel shrub willow (Salix) hybrids. Bioenerg. Res. 8, 259-269.

Serapiglia, M.J., Gouker, F.E., Smart, L.B., 2014. Early selection of novel triploid hybrids of shrub willow with improved biomass yield relative to diploids. BMC Plant Biol. 14, 74.

Shukla, G.K., 1972. Some statistical aspects of partitioning genotype environmental components of variability. Heredity 29, 237-245. 
Sims, J.T., Wolf, A.M., 1995. Recommended Soil Testing Procedures for the Northeastern United States. Agricultural Experiment Station Univ. of Delaware, Newark, Del., Northeastern Regional Pub. No. 493 (2nd edition).

Sixto, H., Gil, P., Ciria, P., Camps, F., Cañellas, I., Voltas, J., 2016. Interpreting genotype-byenvironment interaction for biomass production in hybrid poplars under short-rotation coppice in Mediterranean environments. GCB Bioenergy, 8, 1124-1135.

Sixto, H., Gil, P., Ciria, P., Camps, F., Sánchez, M., Cañellas, I., Voltas, J., 2014. Performance of hybrid poplar clones in short rotation coppice in Mediterranean environments: analysis of genotypic stability. GCB Bioenergy 6, 661-671.

Sleight, N.J., Volk, T.A., 2016. Recently Bred Willow (Salix spp.) Biomass Crops Show Stable Yield Trends Over Three Rotations at Two Sites. Bioenerg. Res., 1-16.

Sleight, N.J., Volk, T.A., Johnson, G.A., Eisenbies, M.H., Shi, S., Fabio, E.S., Pooler, P.S., 2016. Change in Yield Between First and Second Rotations in Willow (Salix spp.) Biomass Crops is Strongly Related to the Level of First Rotation Yield. Bioenerg. Res. 9, 270-287.

Smart, L.B., Cameron, K.D., 2008. Genetic Improvement of Willow (Salix spp.) as a Dedicated Bioenergy Crop, in: Vermerris, W. (Ed.), Genetic Improvement of Bioenergy Crops. Springer New York, New York, NY, pp. 377-396.

Smart, L.B., Cameron, K.D., 2012. Shrub willow, in: Kole, C., Joshi, C.P., Shonnard, D.R. (Eds.), Handbook of Bioenergy Crop Plants. Taylor and Francis Group, Boca Raton, FL, pp. 687-708.

Smart, L.B., Cameron, K.D., Volk, T.A., Abrahamson, L.P., 2008. Breeding, selection, and testing of shrub willow as a dedicated energy crop, NABC Report 19 Agricultural Biofuels: Technology, Sustainability, and Profitability. National Agricultural Biotechnology Council, Ithaca, NY, pp. 85-92.

Smart, L.B., Volk, T.A., Lin, J., Kopp, R.F., Phillips, I.S., Cameron, K.D., White, E.H., Abrahamson, L.P., 2005. Genetic improvement of shrub willow (Salix spp.) crops for bioenergy and environmental applications in the United States. Unasylva 56, 51-55.

Smith, A.B., Cullis, B.R., Thompson, R., 2005. The analysis of crop cultivar breeding and evaluation trials: an overview of current mixed model approaches. J. Agr. Sci. 143, 449-462.

Stott, K.G., 1991. Nomenclature of the promising biomass coppice willows, Salix $\times$ sericans Tausch ex Kern., Salix dasyclados Wimm. and Salix 'Aquatica Gigantea'. Bot. J. Scot. 46, 137-143.

U. S. Department of Energy, 2011. U.S. billion-ton update: Biomass supply for a bioenergy and bioproducts industry. R.D. Perlack and B.J. Stokes (Leads). Oak Ridge National Laboratory. 227p., Oak Ridge, TN.

Volk, T.A., Abrahamson, L.P., Cameron, K.D., Castellano, P., Corbin, T., Fabio, E., Johnson, G., Kuzovkina-Eischen, Y., Labrecque, M., Miller, R., Sidders, D., Smart, L.B., Staver, K., Stanosz, G.R., Van Rees, K.C.J., 2011. Yields of willow biomass crops across a range of sites in North America. Asp. Appl. Biol. 112, 67-74.

Volk, T.A., Abrahamson, L.P., Nowak, C.A., Smart, L.B., Tharakan, P.J., White, E.H., 2006. The development of short-rotation willow in the northeastern United States for bioenergy and bioproducts, agroforestry and phytoremediation. Biomass Bioenerg. 30, 715-727.

Volk, T.A., Heavey, J.P., Eisenbies, M.H., 2016. Advances in shrub-willow crops for bioenergy, renewable products, and environmental benefits. Food Energ. Secur., 97-106.

Walsh, M., de la Torre Ugarte, D., Shapouri, H., Slinsky, S., 2003. Bioenergy crop production in the United States: Potential quantities, land use changes, and economic impacts on the agricultural sector. Environ. Resour. Econ. 24, 313-333.

Wightman, J.L., Duxbury, J.M., Woodbury, P.B., 2015. Land quality and management practices strongly affect greenhouse gas emissions of bioenergy feedstocks. Bioenerg. Res. 8, 1681-1690. 
Table 1 Characteristics of the 21 shrub willow cultivars present in Dataset 1.

\begin{tabular}{|c|c|c|c|c|c|c|c|c|}
\hline Epithet $^{\mathrm{a}}$ & Species/Pedigree & Mother & Father & $\begin{array}{l}\text { Diversity } \\
\text { Group }^{\text {b }}\end{array}$ & Sex & Ploidy $^{\mathrm{c}}$ & Program/ origin & $\begin{array}{l}\text { No. of } \\
\text { trials }\end{array}$ \\
\hline$\underline{\text { SV1 }}$ & S. $\times$ dasyclados & & & 1 & $\mathrm{~F}$ & $2 X$ & Unknown $^{\mathrm{d}}$ & 15 \\
\hline S25 & S. eriocephala & S. erio 16 & S. erio 276 & 4 & $\mathrm{~F}$ & $2 X$ & Canada & 13 \\
\hline Allegany & S. koriyanagi $\times S$. purpurea & $\mathrm{SH} 3$ & 95058 & $6 b$ & $\mathrm{~F}$ & $2 X$ & USA & 14 \\
\hline Onondaga & S. koriyanagi $\times S$. purpurea & $\mathrm{SH} 3$ & 94002 & $6 b$ & M & $2 X$ & USA & 14 \\
\hline 94001 & S. purpurea & & & $6 a$ & M & $2 X$ & Natural accession & 11 \\
\hline Fish Creek & S. purpurea & 94006 & 94001 & $6 a$ & $\mathrm{M}$ & $2 X$ & USA & 15 \\
\hline Wolcott & S. purpurea & 94006 & 94001 & $6 a$ & $\mathrm{~F}$ & $2 X$ & USA & 10 \\
\hline Millbrook & S. purpurea $\times$ S. miyabeana & 95026 & SX64 & 9 & $\mathrm{~F}$ & $3 X$ & USA & 15 \\
\hline Oneida & S. purpurea $\times$ S. miyabeana & 94006 & SX67 & 9 & M & $3 X$ & USA & 15 \\
\hline Oneonta & S. purpurea $\times$ S. miyabeana & 94006 & SX64 & 9 & M & $3 X$ & USA & 12 \\
\hline Fabius & S. viminalis $\times S$. miyabeana & SV2 & SX67 & 8 & $\mathrm{~F}$ & $3 X$ & USA & 13 \\
\hline Otisco & S. viminalis $\times$ S. miyabeana & SV2 & SX64 & 8 & $\mathrm{~F}$ & $3 X$ & USA & 15 \\
\hline Owasco & S. viminalis $\times S$. miyabeana & SV7 & SX64 & 8 & $\mathrm{~F}$ & $3 X$ & USA & 14 \\
\hline Truxton & S. viminalis $\times S$. miyabeana & SV7 & SX64 & 8 & M & $3 X$ & USA & 12 \\
\hline Tully Champion & S. viminalis $\times S$. miyabeana & SV2 & SX67 & 8 & $\mathrm{~F}$ & $3 X$ & USA & 14 \\
\hline Canastota & S. miyabeana & SX61 & SX64 & 5 & M & $4 X$ & USA & 14 \\
\hline Cicero & S. miyabeana & SX61 & SX64 & 5 & $\mathrm{~F}$ & $4 X$ & USA & 10 \\
\hline Marcy & S. miyabeana & SX61 & SX64 & 5 & $\mathrm{~F}$ & $4 X$ & USA & 10 \\
\hline Sherburne & S. miyabeana & SX61 & SX67 & 5 & $\mathrm{~F}$ & $4 X$ & USA & 14 \\
\hline$\underline{\text { SX61 }}$ & S. miyabeana & & & 5 & $\mathrm{~F}$ & $4 X$ & Natural accession & 15 \\
\hline$\underline{\mathrm{SX} 64}$ & S. miyabeana & & & 5 & $\mathrm{M}$ & $4 X$ & Natural accession & 15 \\
\hline
\end{tabular}

${ }^{\mathrm{a}}$ The three check cultivars are underlined

${ }^{\mathrm{b}}$ Diversity group codes are a shorthand reference to cultivar species/pedigrees

${ }^{\mathrm{c}}$ Ploidy level estimated by flow cytometry (Serapiglia et al. 2015)

${ }^{\mathrm{d}}$ Collected in Ontario Canada, but possibly an escaped horticultural hybrid of S. viminalis $\times$ S. caprea $\times$ S. cinerea $($ Stott 1991$)$ 
Table 2 Yield trial locations and environmental covariates for Dataset 1.

\begin{tabular}{|c|c|c|c|c|c|c|c|c|c|c|}
\hline Location & Code & Host institution & $\begin{array}{l}\text { Year } \\
\text { planted }\end{array}$ & LAT & LONG & Elev & Prc & GDD & Tmax & Tmin \\
\hline & & & & & & $(\mathrm{m})$ & $(\mathrm{mm})$ & $\left({ }^{\circ} \mathrm{C}\right)$ & $\left({ }^{\circ} \mathrm{C}\right)$ & $\left({ }^{\circ} \mathrm{C}\right)$ \\
\hline Albion, MI & Albi & Michigan St Univ & 2011 & 42.19 & -84.73 & 312 & 674 & 1313 & 21 & 2 \\
\hline Belleville, NY & Bell & SUNY ESF & 2005 & 41.98 & -78.56 & 145 & 602 & 1274 & 21 & 2 \\
\hline Boisbriand, QU & Bois & Univ Montreal & 2007 & 45.63 & -73.89 & 30 & 651 & 1162 & 20 & 1.2 \\
\hline Brimley, MI & Brim & Michigan St Univ & 2009 & 46.40 & -84.47 & 200 & 564 & 1021 & 19 & 1.7 \\
\hline Constableville, NY & Cons & SUNY ESF & 2006 & 43.56 & -75.53 & 513 & 842 & 812 & 19 & -1.7 \\
\hline Escanaba, MI & Esca & Michigan St Univ & 2008 & 45.77 & -87.20 & 222 & 537 & 1016 & 19 & -0.1 \\
\hline Fredonia, NY & Fred & Cornell Univ & 2008 & 42.44 & -79.29 & 255 & 662 & 1477 & 21 & 4.9 \\
\hline Middlebury, VT & Midd & SUNY ESF & 2007 & 44.01 & -73.20 & 114 & 766 & 1419 & 23 & 2.0 \\
\hline Potsdam, NY & Pots & SUNY Potsdam & 2009 & 44.67 & -74.97 & 134 & 714 & 1318 & 21 & 2 \\
\hline Saskatoon, SK & Sask & Univ Saskatchewan & 2007 & 52.13 & -106.61 & 510 & 345 & 767 & 18 & -4.1 \\
\hline Savoy, IL & Savo & Univ Illinois & 2010 & 40.07 & -88.20 & 224 & 618 & 2097 & 25 & 6 \\
\hline Skandia, MI & Skan & Michigan St Univ & 2009 & 46.36 & -87.24 & 287 & 581 & 870 & 18 & 0.1 \\
\hline Storrs, CT & Stor & Univ Connecticut & 2009 & 41.80 & -72.23 & 198 & 848 & 1487 & 21 & 5.4 \\
\hline Tully, NY & Tull & SUNY ESF & 2005 & 42.79 & -76.12 & 379 & 816 & 1155 & 20 & 2 \\
\hline Waseca, MN & Wase & Univ Minn & 2006 & 44.06 & -93.54 & 349 & 653 & 1459 & 22 & 1.7 \\
\hline
\end{tabular}

LAT, Latitude (decimal degrees); LONG, longitude (decimal degrees); Elev, elevation; Prc, growing season (April-Oct) precipitation $\mathrm{Y}$; GDD, annual growing degree days (base $\left.10^{\circ} \mathrm{C}\right)$; Tmax, growing season mean maximum temperature $\left({ }^{\circ} \mathrm{C}\right)$; Tmin, annual mean minimum temperature $\left({ }^{\circ} \mathrm{C}\right)$. 
Table 2 Continued.

\begin{tabular}{lllllll}
\hline Location & Code & Rad & SOM & pH & soilP & soilK \\
\hline & & $\begin{array}{c}\left(\mathrm{MJ} \mathrm{m}^{-}\right. \\
\left.\text {day }^{-1}\right)\end{array}$ & $(\%)$ & & $\left(\mathrm{mg} \mathrm{kg}^{-1}\right)$ & $\left(\mathrm{mg} \mathrm{kg}^{-1}\right)$ \\
Albion, MI & Albi & 3790 & 2.0 & 6.37 & 5.6 & 128.3 \\
Belleville, NY & Bell & 3957 & 3.3 & 6.49 & 7.8 & 109.4 \\
Boisbriand, QU & Bois & 3576 & 4.0 & 6.09 & 1.0 & 48.2 \\
Brimley, MI & Brim & 3882 & 4.0 & 5.25 & 1.0 & 69.6 \\
Constableville, NY & Cons & 3572 & 8.2 & 5.66 & 1.0 & 71.8 \\
Escanaba, MI & Esca & 4008 & 2.8 & 6.10 & 1.0 & 30.3 \\
Fredonia, NY & Fred & 3895 & 3.6 & 4.80 & 8.3 & 122.5 \\
Middlebury, VT & Midd & 3548 & 6.8 & 6.70 & 27.3 & 150.4 \\
Potsdam, NY & Pots & 3470 & 6.8 & 5.65 & 1.5 & 48.8 \\
Saskatoon, SK & Sask & 3535 & 4.5 & 7.07 & 10.6 & 326.5 \\
Savoy, IL & Savo & 3977 & 2.4 & 6.27 & 1.0 & 84.7 \\
Skandia, MI & Skan & 3865 & 3.6 & 6.47 & 1.0 & 41.5 \\
Storrs, CT & Stor & 3785 & 3.4 & 6.12 & 1.2 & 72.8 \\
Tully, NY & Tull & 3674 & 3.2 & 4.99 & 2.4 & 77.2 \\
Waseca, MN & Wase & 3802 & 5.7 & 5.40 & 42.9 & 216.9 \\
\hline
\end{tabular}

Rad, growing season solar radiation; SOM, soil organic matter; $\mathrm{pH}$, soil pH; SoilP, soil phosphorus; SoilK, soil potassium. Climatic variables are four-year means across the first harvest rotation. 
Table 3 Characteristics of the 25 shrub willow genotypes present in Dataset 2.

\begin{tabular}{|c|c|c|c|c|c|c|c|c|}
\hline $\begin{array}{l}\text { Clone ID/ } \\
\text { Epithet }\end{array}$ & Species/Pedigree & Mother & Father & $\begin{array}{l}\text { Diversity } \\
\text { Group }^{\text {a }}\end{array}$ & Sex & Ploidy $^{b}$ & $\begin{array}{l}\text { Program/ } \\
\text { originc }^{2}\end{array}$ & $\begin{array}{l}\text { No. of } \\
\text { trials }\end{array}$ \\
\hline 94006 & S. purpurea & & & $6 a$ & $\mathrm{~F}$ & $2 X$ & Nat acc & 5 \\
\hline $05 X-293-047$ & S. purpurea & 05-01-002 & Fish Creek & $6 a$ & $\mathrm{M}$ & $2 X$ & USA & 3 \\
\hline Fish Creek & S. purpurea & 94006 & 94001 & $6 a$ & M & $2 X$ & USA & 5 \\
\hline 01X-265-019 & S. koriyanagi $\times S$. purpurea & SH3 & 94001 & $6 b$ & M & $2 X$ & USA & 5 \\
\hline Dimitrios & $(S$. schwerinii $\times S$. viminalis $) \times S$. aeygyptiaca & Tora & & 14 & M & $3 \mathrm{X}$ & Sweden & 5 \\
\hline $02 X-326-010$ & S. miyabeana $\times(S$. schwerinii $\times . S$. viminalis $)$ & $9970-021$ & Olof & 10 & M & $3 \mathrm{X}$ & USA & 5 \\
\hline $02 X-326-015$ & S. miyabeana $\times($ S. schwerinii $\times$. S. viminalis $)$ & $9970-021$ & Olof & 10 & M & $3 \mathrm{X}$ & USA & 5 \\
\hline Victor & S. purpurea $\times S$. miyabeana & 00-01-088 & SX67 & 9 & $\mathrm{~F}$ & $3 \mathrm{X}$ & USA & 5 \\
\hline $05 X-291-050$ & S. purpurea $\times S$. miyabeana & $00-01-088$ & SX67 & 9 & M & $3 \mathrm{X}$ & USA & 5 \\
\hline Sterling & S. purpurea $\times S$. miyabeana & 05-01-002 & SX64 & 9 & M & $3 X$ & USA & 3 \\
\hline Hopewell & S. purpurea $\times S$. miyabeana & $05-01-002$ & SX64 & 9 & $\mathrm{~F}$ & $3 X$ & USA & 3 \\
\hline Millbrook & S. purpurea $\times S$. miyabeana & 95026 & SX64 & 9 & $\mathrm{~F}$ & $3 X$ & USA & 5 \\
\hline Saratoga & S. purpurea $\times S$. miyabeana & 95026 & SX64 & 9 & $\mathrm{~F}$ & $3 X$ & USA & 5 \\
\hline Tonawanda & $(S$. koriyanagi $\times S$. purpurea $) \times S$. miyabeana & $99239-015$ & SX67 & $9 b$ & $\mathrm{~F}$ & $3 \mathrm{X}$ & USA & 5 \\
\hline Geneva Giant & $(S$. koriyanagi $\times S$. purpurea $) \times S$. miyabeana & 99239-015 & SX67 & $9 b$ & $\mathrm{~F}$ & $3 X$ & USA & 5 \\
\hline Sheridan & S. viminalis $\times(S$. viminalis $\times S$. miyabeana $)$ & SV2 & $99207-019$ & 8 & $\mathrm{~F}$ & $3 X$ & USA & 5 \\
\hline Seneca Chief & S. viminalis $\times S$. miyabeana & SV7 & $9970-037$ & 8 & $\mathrm{~F}$ & $3 X$ & USA & 5 \\
\hline Fabius & S. viminalis $\times S$. miyabeana & SV2 & SX67 & 8 & $\mathrm{~F}$ & $3 X$ & USA & 5 \\
\hline LA970253 & S. viminalis $\times S$. miyabeana & & & 8 & $\mathrm{~F}$ & $3 X$ & UK & 4 \\
\hline Otisco & S. viminalis $\times S$. miyabeana & SV2 & SX64 & 8 & $\mathrm{~F}$ & $3 X$ & USA & 5 \\
\hline Preble & S. viminalis $\times S$. miyabeana & SV2 & $9970-037$ & 8 & $\mathrm{~F}$ & $3 X$ & USA & 5 \\
\hline Tully Champion & S. viminalis $\times S$. miyabeana & SV2 & SX67 & 8 & $\mathrm{~F}$ & $3 X$ & USA & 3 \\
\hline Canastota & S. miyabeana & SX61 & SX64 & 5 & M & $4 X$ & USA & 3 \\
\hline$\underline{\text { SX61 }}$ & S. miyabeana & & & 5 & $\mathrm{~F}$ & $4 X$ & Nat acc & 5 \\
\hline India & S. dasyclados & & & 15 & $\mathrm{M}$ & $6 \mathrm{X}$ & Canada & 5 \\
\hline
\end{tabular}


${ }^{a}$ Diversity group codes are a direct reference to cultivar species/pedigree

${ }^{\mathrm{b}}$ Ploidy level estimated by flow cytometry (Serapiglia et al. 2015)

${ }^{\mathrm{c}} \mathrm{Nat}$ acc, natural accession 
Table 4 Yield trial locations and environmental covariates for Dataset 2.

\begin{tabular}{|c|c|c|c|c|c|c|}
\hline & & Escanaba, MI & $\begin{array}{c}\text { Fredonia, NY } \\
\text { Amended }\end{array}$ & $\begin{array}{c}\text { Fredonia, NY } \\
\text { Control }\end{array}$ & Geneva, NY & $\begin{array}{c}\text { Rock Springs, } \\
\text { PA }\end{array}$ \\
\hline LAT & & 45.77 & 42.44 & 42.44 & 42.88 & 40.70 \\
\hline LONG & & -87.20 & -79.29 & -79.29 & -77.00 & -77.96 \\
\hline Elev & (m) & 219.1 & 255.9 & 255.9 & 167.0 & 403.7 \\
\hline Prc & $(\mathrm{mm})$ & 515.2 & 658.9 & 658.9 & 621.2 & 744.3 \\
\hline GDD & $\left({ }^{\circ} \mathrm{C}\right)$ & 981.7 & 1431.3 & 1431.3 & 1466.6 & 1651.5 \\
\hline Tmax & $\left({ }^{\circ} \mathrm{C}\right)$ & 19.3 & 20.9 & 20.9 & 21.4 & 22.0 \\
\hline Tmin & $\left({ }^{\circ} \mathrm{C}\right)$ & -0.2 & 4.1 & 4.1 & 4.1 & 5.6 \\
\hline $\operatorname{Rad}$ & $\left(\mathrm{MJ} \mathrm{m}^{-1} \mathrm{day}^{-1}\right)$ & 3723.8 & 3624.1 & 3624.1 & 3513.7 & 3484.4 \\
\hline SOM & $(\%)$ & 2.5 & 4.1 & 3.8 & 2.3 & 4.7 \\
\hline $\mathrm{pH}$ & & 7.0 & 6.2 & 6.0 & 6.5 & 5.6 \\
\hline soilP & $\left(\mathrm{mg} \mathrm{kg}^{-1}\right)$ & 11.8 & 1.1 & 1.0 & 1.0 & 1.0 \\
\hline soilK & $\left(\mathrm{mg} \mathrm{kg}^{-1}\right)$ & 71.1 & 104.6 & 83.9 & 44.7 & 90.6 \\
\hline soilCa & $\left(\mathrm{mg} \mathrm{kg}^{-1}\right)$ & 1344.4 & 1526.9 & 1193.5 & 1414.6 & 1163.4 \\
\hline SoilAl & $\left(\mathrm{mg} \mathrm{kg}^{-1}\right)$ & 9.8 & 55.3 & 48.9 & 21.2 & 44.4 \\
\hline
\end{tabular}

LAT, Latitude (decimal degrees); LONG, longitude (decimal degrees); Elev, elevation; Prc, growing season (April-Oct) precipitation; GDD, annual growing degree days (base $10{ }^{\circ} \mathrm{C}$ ); Tmax, growing season mean maximum temperature; Tmin, annual mean minimum temperature; Rad, growing season solar radiation; SOM, soil organic matter ; $\mathrm{pH}$, soil pH; SoilP, soil Phosphorus; SoilK, soil potassium. Climatic variables are four-year means across the first harvest rotation. 
Table 5 Fit statistics for mixed models tested in Dataset 1.

\begin{tabular}{|c|c|c|c|c|c|c|c|c|c|}
\hline \multirow[b]{2}{*}{ Model } & \multicolumn{3}{|c|}{$\begin{array}{l}\text { Homogeneous } \\
\text { Error Variance }\end{array}$} & \multicolumn{3}{|c|}{$\begin{array}{l}\text { Heterogeneous } \\
\text { Error Variance }\end{array}$} & \multicolumn{3}{|c|}{ Res $L^{\mathrm{a}}{ }^{\mathrm{a}}$ Ratio Tests } \\
\hline & $p^{\mathbf{b}}$ & $\begin{array}{c}-2 \text { Res } \\
\text { LL }\end{array}$ & $\mathrm{AIC}^{\mathrm{c}}$ & $p$ & $\begin{array}{c}-2 \text { Res } \\
\text { LL }\end{array}$ & AIC & $X^{2}$ & DF & $P$-value \\
\hline Simple additive & 3 & 4372.9 & 4378.9 & 17 & 4120.2 & 4154.2 & 252.7 & 14 & $<0.0001$ \\
\hline Compound symmetry & 4 & 4292.7 & 4300.7 & 18 & 4052.4 & 4088.4 & 240.3 & 14 & $<0.0001$ \\
\hline Heterogeneous CS & 24 & 4256.9 & 4304.9 & 38 & 3999.6 & 4075.6 & 257.3 & 14 & $<0.0001$ \\
\hline Shukla's & 24 & 4259.9 & 4301.9 & 38 & 4018.6 & 4090.6 & 241.3 & 14 & $<0.0001$ \\
\hline Finlay-Wilkinson & 24 & 4255.7 & 4303.7 & 38 & 3995.8 & 4071.8 & 259.9 & 14 & $<0.0001$ \\
\hline Eberhart-Russell & 44 & $\underline{4212.9}$ & 4290.9 & 58 & $\underline{\mathbf{3 9 5 3 . 8}}$ & $\underline{4051.8}$ & 259.1 & 14 & $<0.0001$ \\
\hline AMMI-1 & 25 & $\overline{4238.9}$ & $\underline{4288.9}$ & 39 & 3988.3 & $\overline{4066.3}$ & 250.6 & 14 & $<0.0001$ \\
\hline AMMI-2 & 45 & $\underline{4196.8}$ & $\underline{4286.8}$ & 59 & $\underline{3946.5}$ & $\underline{4064.5}$ & 250.3 & 14 & $<0.0001$ \\
\hline
\end{tabular}

${ }^{\mathrm{a}}$ Res LL, Residual log likelihood ratio tests, where the Chi-squared statistic is the difference in the -2 log likelihood, and degrees of freedom (DF) is the difference in the number of parameters, between homogeneous and heterogeneous cases.

${ }^{b}$ Number of parameters estimated in the variance-covariance for each model including the effect of block (nested within environment).

${ }^{c}$ AIC, Akaike information criterion. Bold and underlined values of -2 Res LL and AIC indicate best model fit. 
Table 6 Variance parameters for best fitting models under heterogeneous residual error variance according to AIC for Dataset 1.

\begin{tabular}{|c|c|c|c|c|c|c|c|c|c|c|c|c|}
\hline \multirow[b]{2}{*}{ Genotype } & \multicolumn{6}{|c|}{ Eberhart-Russell } & \multicolumn{6}{|c|}{ AMMI-2 } \\
\hline & $\begin{array}{c}\text { LS } \\
\text { Mean } \\
\end{array}$ & SE & $\lambda_{\mathbf{i}}$ & SE & $\sigma_{i}^{2}$ & SE & $\begin{array}{c}\text { LS } \\
\text { Mean } \\
\end{array}$ & SE & $\lambda_{\mathrm{i}, 1}$ & SE & $\lambda_{\mathrm{i}, 2}$ & SE \\
\hline Fabius & 8.29 & 1.03 & 3.96 & 0.79 & 0.09 & 0.15 & 8.08 & 0.95 & 3.08 & 1.01 & 0.86 & 0.70 \\
\hline Oneonta & 7.51 & 0.89 & 3.40 & 0.69 & 0.10 & 0.21 & 7.52 & 0.89 & 2.71 & 0.91 & 1.00 & 0.45 \\
\hline SX64 & 7.50 & 0.86 & 3.24 & 0.67 & 0.28 & 0.43 & 7.49 & 0.85 & 2.49 & 0.89 & 1.05 & 0.42 \\
\hline Marcy & 7.47 & 1.03 & 3.97 & 0.79 & 0 & & 7.32 & 0.98 & 3.12 & 1.01 & 1.14 & 0.68 \\
\hline Tully Champion & 7.44 & 0.77 & 2.69 & 0.63 & 1.12 & 0.74 & 7.35 & 0.68 & 1.67 & 0.83 & 0.72 & 0.44 \\
\hline Canastota & 7.42 & 0.92 & 3.52 & 0.70 & 0 & 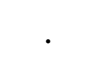 & 7.43 & 0.90 & 2.74 & 0.96 & 1.19 & 0.49 \\
\hline SX61 & 7.36 & 0.86 & 3.27 & 0.67 & 0.22 & 0.23 & 7.44 & 0.85 & 2.57 & 0.88 & 0.81 & 0.41 \\
\hline Oneida & 7.26 & 0.82 & 3.10 & 0.63 & 0.13 & 0.23 & 7.28 & 0.83 & 2.56 & 0.81 & 0.41 & 0.40 \\
\hline Otisco & 7.25 & 0.75 & 2.78 & 0.59 & 0.37 & 0.39 & 7.24 & 0.74 & 2.02 & 0.83 & 0.81 & 0.38 \\
\hline Fish Creek & 7.18 & 0.93 & 3.58 & 0.71 & 0 & 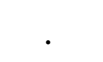 & 7.20 & 0.91 & 2.98 & 0.89 & -0.04 & 0.46 \\
\hline Millbrook & 7.17 & 0.83 & 3.17 & 0.63 & 0 & . & 7.21 & 0.83 & 2.59 & 0.83 & 0.36 & 0.38 \\
\hline Truxton & 6.90 & 0.85 & 3.17 & 0.67 & 0.28 & 0.27 & 6.75 & 0.81 & 2.17 & 0.90 & 1.21 & 0.54 \\
\hline Cicero & 6.64 & 1.05 & 3.99 & 0.85 & 0 & . & 6.48 & 1.01 & 3.22 & 1.04 & 1.05 & 0.69 \\
\hline Owasco & 6.63 & 0.70 & 2.66 & 0.55 & 0 & . & 6.65 & 0.72 & 1.99 & 0.78 & 0.21 & 0.32 \\
\hline Sherburne & 6.44 & 0.82 & 3.12 & 0.62 & 0 & . & 6.45 & 0.82 & 2.41 & 0.86 & 0.81 & 0.40 \\
\hline SV1 & 6.40 & 0.89 & 3.01 & 0.75 & 2.58 & 1.26 & 6.31 & 0.77 & 2.21 & 0.91 & -0.70 & 0.48 \\
\hline 94001 & 6.16 & 0.77 & 2.70 & 0.62 & 0.66 & 0.57 & 6.17 & 0.77 & 2.24 & 0.82 & -0.19 & 0.38 \\
\hline Onondaga & 5.98 & 0.72 & 2.73 & 0.56 & 0 & 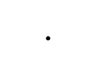 & 5.96 & 0.78 & 2.25 & 0.83 & -0.52 & 0.35 \\
\hline Allegany & 5.96 & 0.69 & 2.61 & 0.53 & 0 & . & 6.02 & 0.74 & 2.09 & 0.77 & 0 & . \\
\hline Wolcott & 5.84 & 0.87 & 2.98 & 0.81 & 0.94 & 0.96 & 6.07 & 0.86 & 2.61 & 0.90 & -0.02 & 0.57 \\
\hline \multirow[t]{4}{*}{ S25 } & 4.96 & 0.65 & 2.24 & 0.52 & 0.45 & 0.45 & 4.91 & 0.63 & 1.36 & 0.76 & 0.39 & 0.40 \\
\hline & & & & & & & $\sigma_{\mathrm{ENV}}^{2}$ & & 3.66 & 2.31 & & \\
\hline & & & & & & & $\sigma_{\beta}^{2}$ & & 0.06 & 0.05 & & \\
\hline & $\sigma_{\mathrm{BLK}}^{2}$ & & 0.91 & 0.24 & & & $\sigma_{\text {BLK }}^{2}$ & & 0.90 & 0.23 & & \\
\hline
\end{tabular}




\begin{tabular}{|c|c|c|c|c|c|c|c|}
\hline \multirow[t]{15}{*}{$\sigma_{\mathrm{RES} j}^{2}$} & Albion & 0.99 & 0.19 & \multirow[t]{15}{*}{$\sigma_{\mathrm{RES} j}^{2}$} & Albion & 0.92 & 0.18 \\
\hline & Bellev & 3.92 & 0.88 & & Bellev & 1.86 & 0.39 \\
\hline & Boisbr & 5.84 & 1.00 & & Boisbr & 6.02 & 1.01 \\
\hline & Brimle & 0.41 & 0.08 & & Brimle & 0.43 & 0.08 \\
\hline & Consta & 4.14 & 0.73 & & Consta & 4.53 & 0.79 \\
\hline & Escana & 2.17 & 0.45 & & Escana & 2.20 & 0.46 \\
\hline & Fredon & 1.38 & 0.24 & & Fredon & 1.35 & 0.25 \\
\hline & Middle & 3.65 & 0.66 & & Middle & 3.73 & 0.81 \\
\hline & Postdam & 1.05 & 0.22 & & Postdam & 1.20 & 0.26 \\
\hline & Saskat & 1.08 & 0.20 & & Saskat & 1.12 & 0.21 \\
\hline & Savoy & 2.98 & 0.67 & & Savoy & 3.36 & 0.72 \\
\hline & Skandi & 0.65 & 0.12 & & Skandi & 0.67 & 0.12 \\
\hline & Storrs & 6.81 & 1.29 & & Storrs & 6.66 & 1.28 \\
\hline & Tully & 0.66 & 0.13 & & Tully & 0.72 & 0.15 \\
\hline & Waseca & 1.48 & 0.25 & & Waseca & 2.03 & 0.39 \\
\hline
\end{tabular}


Table 7 Fit statistics for mixed models tested in Dataset 2.

\begin{tabular}{|c|c|c|c|c|c|c|c|c|c|}
\hline \multirow[b]{2}{*}{ Model } & \multicolumn{3}{|c|}{$\begin{array}{l}\text { Homogeneous } \\
\text { Error Variance }\end{array}$} & \multicolumn{3}{|c|}{$\begin{array}{l}\text { Heterogeneous } \\
\text { Error Variance }\end{array}$} & \multicolumn{3}{|c|}{ Res LL ${ }^{\mathrm{a}}$ Ratio Tests } \\
\hline & $p^{\mathbf{b}}$ & $\begin{array}{c}-2 \text { Res } \\
\text { LL }\end{array}$ & $\mathrm{AIC}^{\mathrm{c}}$ & $p$ & $\begin{array}{c}-2 \text { Res } \\
\text { LL }\end{array}$ & AIC & $X^{2}$ & DF & $P$-value \\
\hline Simple additive & 3 & 1931.3 & 1937.3 & 7 & 1868.6 & 1882.6 & 62.7 & 4 & $<0.0001$ \\
\hline Compound Symmetry & 4 & 1900.6 & 1908.6 & 8 & 1839.4 & 1855.4 & 61.2 & 4 & $<0.0001$ \\
\hline Heterogeneous CS & 28 & 1850.6 & 1906.6 & 32 & 1784.5 & 1848.5 & 66.1 & 4 & $<0.0001$ \\
\hline Shukla's & 28 & 1880 & 1924 & 32 & 1815.7 & 1865.7 & 64.3 & 4 & $<0.0001$ \\
\hline Finlay-Wilkinson & 28 & 1852.8 & 1908.8 & 32 & 1784.5 & 1848.5 & 68.3 & 4 & $<0.0001$ \\
\hline Eberhart-Russell & 52 & $\underline{1834.2}$ & 1912.2 & 56 & $\underline{1767.6}$ & 1853.6 & 66.6 & 4 & $<0.0001$ \\
\hline AMMI-1 & 29 & 1850.9 & $\underline{1908.9}$ & 33 & 1782.4 & $\underline{1848.4}$ & 68.5 & 4 & $<0.0001$ \\
\hline AMMI-2 & 53 & $\underline{\mathbf{1 7 9 9 . 8}}$ & $\underline{1899.8}$ & 57 & $\underline{1733.9}$ & $\underline{1841.9}$ & 65.9 & 4 & $<0.0001$ \\
\hline
\end{tabular}

${ }^{a}$ Res LL, Residual log likelihood ratio tests, where the Chi-squared statistic is the difference in the -2 log likelihood, and degrees of freedom (DF) is the difference in the number of parameters, between homogeneous and heterogeneous cases.

${ }^{b}$ Number of parameters estimated in the variance-covariance for each model including the effect of block (nested within environment).

${ }^{c}$ AIC, Akaike information criterion. Bold and underlined values of -2 Res LL and AIC indicate best model fit. 
Table 8 Variance parameters for best fitting models under heterogeneous residual error variance according to AIC for Dataset 2.

\begin{tabular}{|c|c|c|c|c|c|c|c|c|c|c|}
\hline \multirow[b]{2}{*}{ Genotype } & \multicolumn{4}{|c|}{ AMMI-1 } & \multicolumn{6}{|c|}{ AMMI-2 } \\
\hline & LS Mean & SE & $\lambda_{\mathrm{i}, \mathbf{1}}$ & SE & LS Mean & SE & $\lambda_{\mathrm{i}, 1}$ & SE & $\lambda_{i, 2}$ & SE \\
\hline LA970253 & 9.20 & 1.80 & 4.00 & 1.73 & 7.52 & 1.20 & 0.71 & 2.02 & 3.18 & 1.42 \\
\hline Tonawanda & 8.67 & 1.57 & 3.48 & 1.47 & 8.60 & 1.58 & 3.72 & 1.41 & 0.39 & 0.64 \\
\hline Preble & 8.67 & 1.75 & 3.95 & 1.63 & 8.65 & 1.83 & 4.32 & 1.62 & 0.44 & 0.68 \\
\hline Fabius & 8.53 & 1.21 & 2.53 & 1.19 & 8.40 & 1.23 & 2.87 & 1.12 & 0.15 & 0.56 \\
\hline Victor & 8.25 & 1.57 & 3.49 & 1.49 & 8.45 & 1.50 & 3.05 & 1.60 & 2.08 & 0.91 \\
\hline Tully Champion & 7.80 & 1.59 & 3.39 & 2.35 & 10.33 & 0.58 & 0.39 & 1.75 & -1.15 & 1.28 \\
\hline Saratoga & 7.78 & 1.33 & 2.87 & 1.35 & 7.93 & 1.31 & 2.74 & 1.36 & 1.59 & 0.76 \\
\hline Sterling & 7.76 & 1.05 & 1.98 & 1.14 & 9.84 & 1.69 & 2.54 & 2.00 & 3.22 & 2.22 \\
\hline Hopewell & 7.56 & 1.17 & 2.36 & 1.25 & 9.97 & 1.91 & 3.05 & 2.31 & 3.72 & 2.32 \\
\hline Millbrook & 7.39 & 1.21 & 2.56 & 1.27 & 7.46 & 1.26 & 2.84 & 1.21 & 0.92 & 0.60 \\
\hline Seneca Chief & 7.31 & 1.05 & 2.13 & 1.22 & 7.30 & 1.29 & 2.96 & 1.16 & 0 & . \\
\hline Otisco & 7.26 & 1.25 & 2.64 & 1.24 & 7.16 & 1.32 & 3.09 & 1.19 & 0.11 & 0.55 \\
\hline Geneva Giant & 7.24 & 1.42 & 3.09 & 1.40 & 7.45 & 1.39 & 2.68 & 1.55 & 2.17 & 0.92 \\
\hline SX61 & 6.90 & 1.41 & 3.08 & 1.39 & 6.92 & 1.48 & 3.43 & 1.34 & 0.60 & 0.60 \\
\hline Canastota & 6.67 & 1.52 & 3.52 & 2.79 & 6.47 & 1.80 & 4.13 & 2.21 & 1.06 & 1.30 \\
\hline $02 X-326-015$ & 6.54 & 1.14 & 2.35 & 1.17 & 6.42 & 1.12 & 2.59 & 1.04 & 0.17 & 0.52 \\
\hline $05 X-291-050$ & 6.29 & 0.87 & 1.60 & 1.08 & 6.33 & 0.95 & 2.10 & 0.94 & 0.61 & 0.54 \\
\hline Fish Creek & 6.21 & 0.73 & 1.08 & 0.94 & 6.23 & 0.71 & 1.34 & 0.82 & 0.88 & 0.56 \\
\hline Sheridan & 6.17 & 1.09 & 2.20 & 1.13 & 6.14 & 1.09 & 2.45 & 1.04 & 0.61 & 0.53 \\
\hline 01X-265-019 & 6.07 & 1.08 & 2.16 & 1.10 & 5.91 & 1.12 & 2.54 & 1.01 & 0 & . \\
\hline $02 X-326-010$ & 5.99 & 0.98 & 1.91 & 1.11 & 5.83 & 1.21 & 2.75 & 1.13 & -0.63 & 0.55 \\
\hline Dimitrios & 5.78 & 0.64 & 0.20 & 0.81 & 5.59 & 0.42 & 0.18 & 0.61 & 0.66 & 0.53 \\
\hline 05X-293-047 & 5.34 & 0.73 & 0.66 & 0.89 & 6.73 & 1.10 & 1.07 & 1.39 & 2.30 & 1.81 \\
\hline 94006 & 5.09 & 0.83 & 1.45 & 1.02 & 5.12 & 0.82 & 1.68 & 0.87 & 0.82 & 0.56 \\
\hline India & 3.49 & 0.70 & 0.83 & 0.83 & 3.34 & 0.50 & 0.88 & 0.60 & 0.41 & 0.47 \\
\hline
\end{tabular}




\begin{tabular}{clccccc}
$\sigma_{\text {ENV }}^{2}$ & & 1.41 & 1.98 & $\sigma_{\text {ENV }}^{2}$ & 0 &. \\
$\sigma_{\beta}^{2}$ & & 0.04 & 0.13 & $\sigma_{\beta}^{2}$ & 0 &. \\
$\sigma_{\text {BLK }}^{2}$ & & 0.63 & 0.28 & $\sigma_{\text {BLK }}^{2}$ & 0.63 & 0.27 \\
& & & & & \\
$\sigma_{\text {RES } j}^{2}$ & Escanaba & 5.48 & 0.97 & $\sigma_{\text {RES } j}^{2}$ & 4.87 & 0.82 \\
& Fredonia, Amended & 2.27 & 0.42 & & 2.32 & 0.39 \\
& Fredonia, Control & 0.83 & 0.14 & & 0.77 & 0.12 \\
& Geneva & 4.64 & 0.83 & & 4.01 & 0.63 \\
& Rock Springs & 4.02 & 0.82 & & 2.92 & 0.51 \\
\hline
\end{tabular}




\section{Figure captions}

Fig. 1. Mixed model AMMI-2 biplot for Dataset 1, representing the first two factor scores for environments in red and genotypes in blue with names truncated to four letters. Environment symbol sizes are scaled to represent relative overall mean yields. Genotype symbols are color coded by species/pedigree (see Table 1).

Fig. 2. Partial least squares biplot for Dataset 1, representing the first two factors for environment scores (red), and genotype (blue) and environmental covariate (green) loadings, with environment and genotype names truncated. Genotype symbols are color coded by species/pedigree (see Table 1).

Fig. 3. Mixed model AMMI-1 biplot showing genotype least square means for yield and first factor scores for Dataset 2. Genotype names have been truncated. Genotype symbols are color coded by species/pedigree (see Table 3). Vertical and horizontal reference lines represent the mean yield and mean factor score, respectively.

Fig. 4. Partial least squares biplot for Dataset 2, representing the first two factors for environment scores (red), and genotype (blue) and environmental covariate (green) loadings, with environment and genotype names truncated to four letters. Genotype symbols are color coded by species/pedigree (see Table 3). 


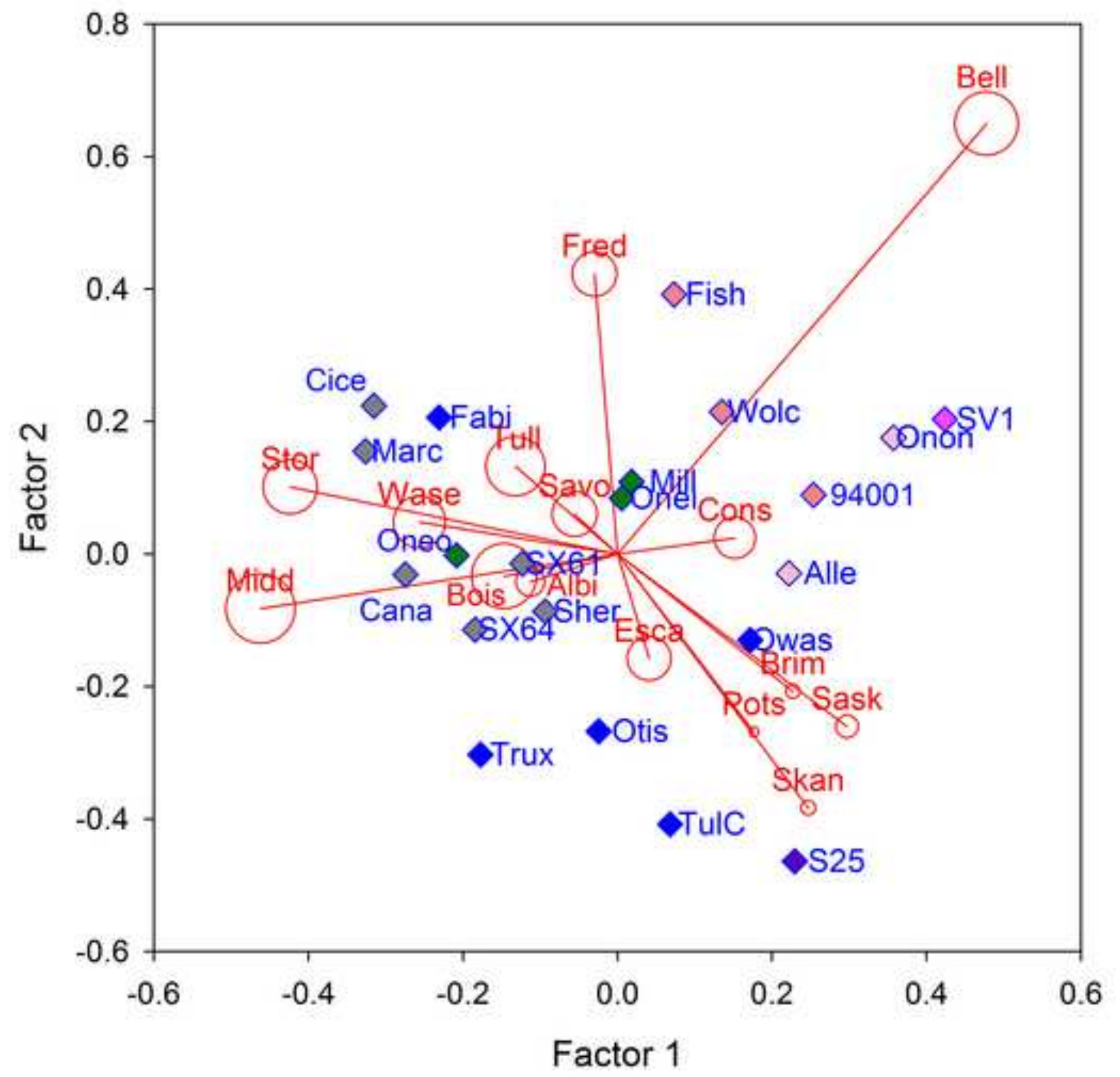




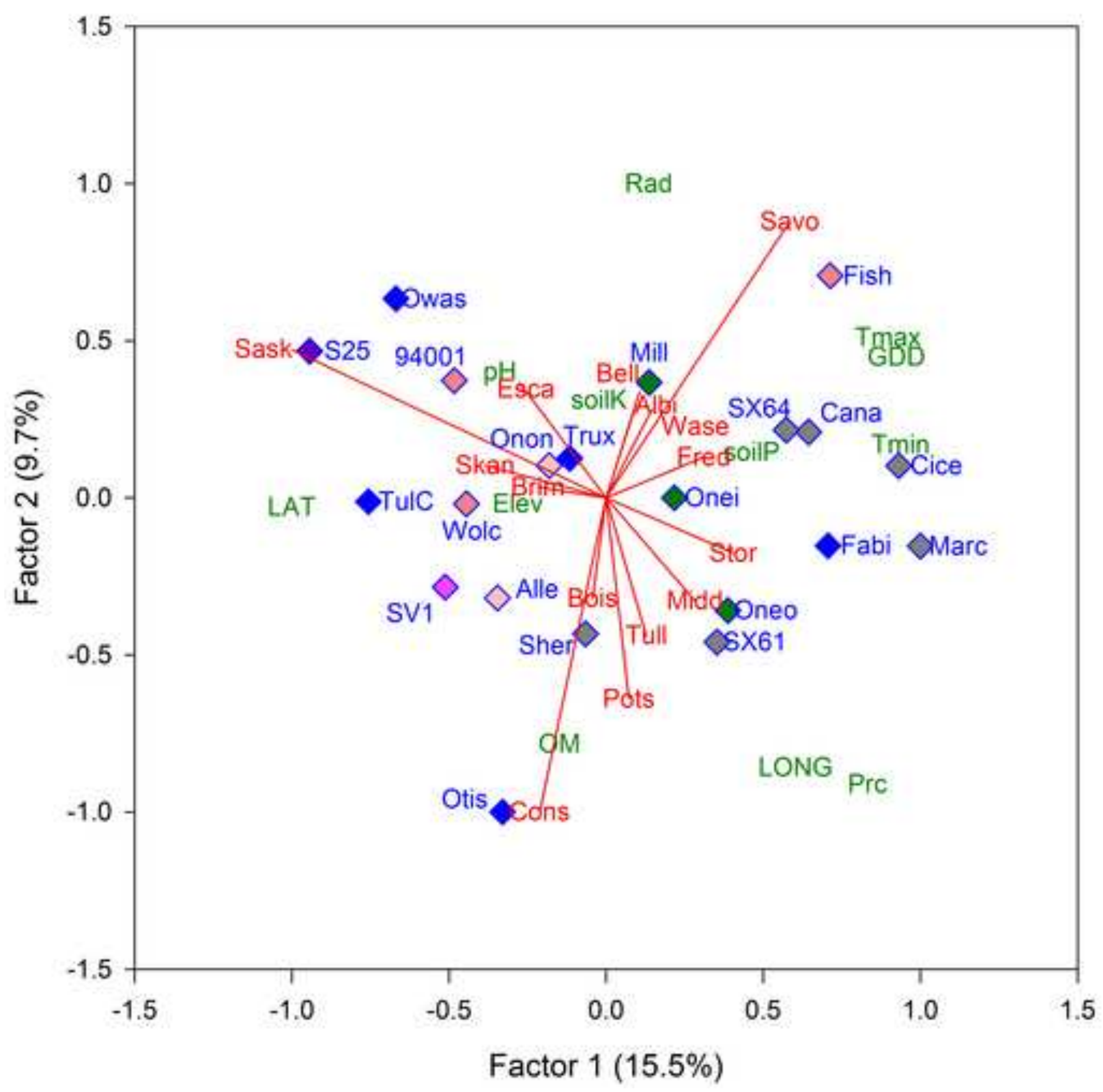




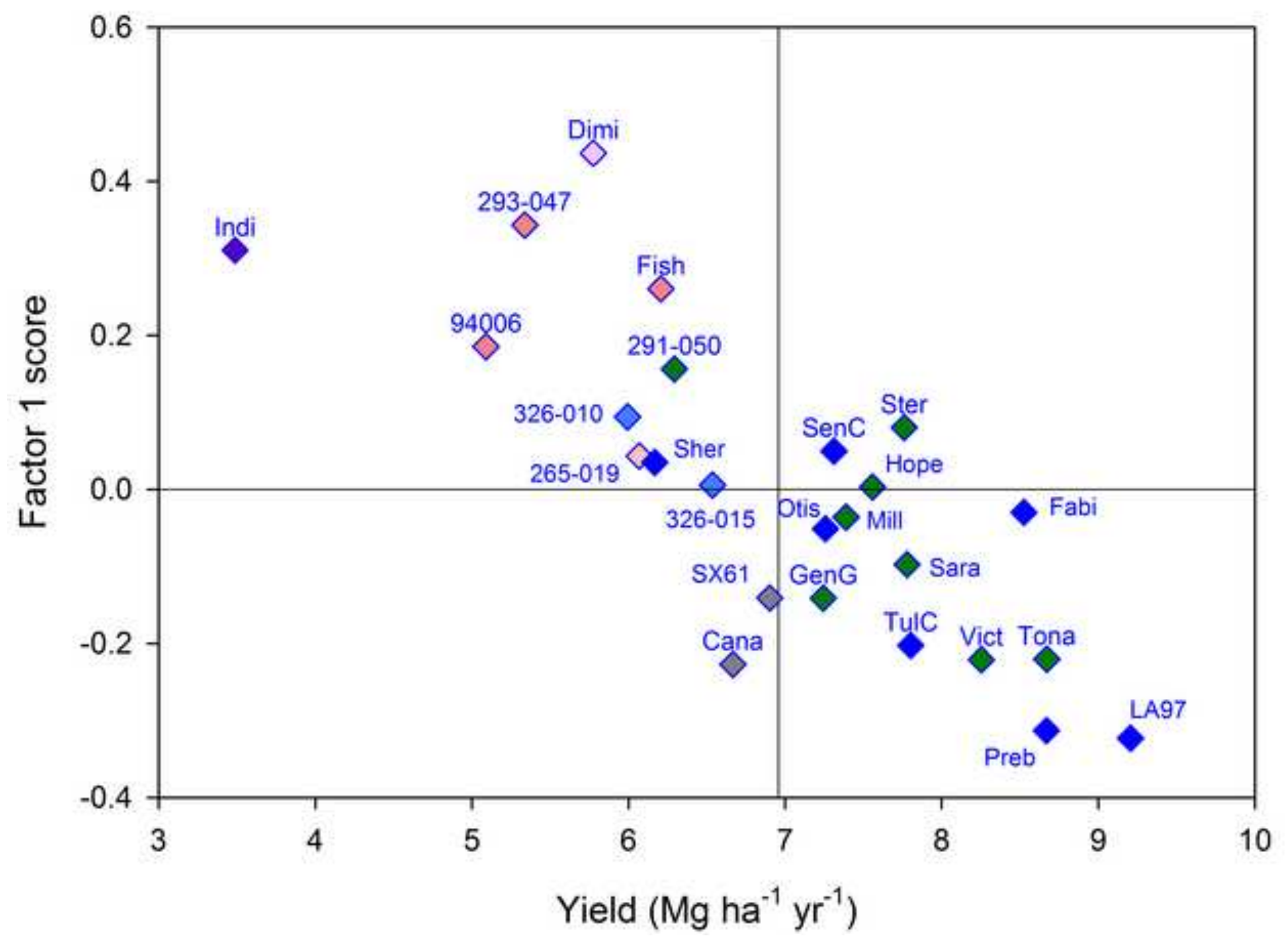




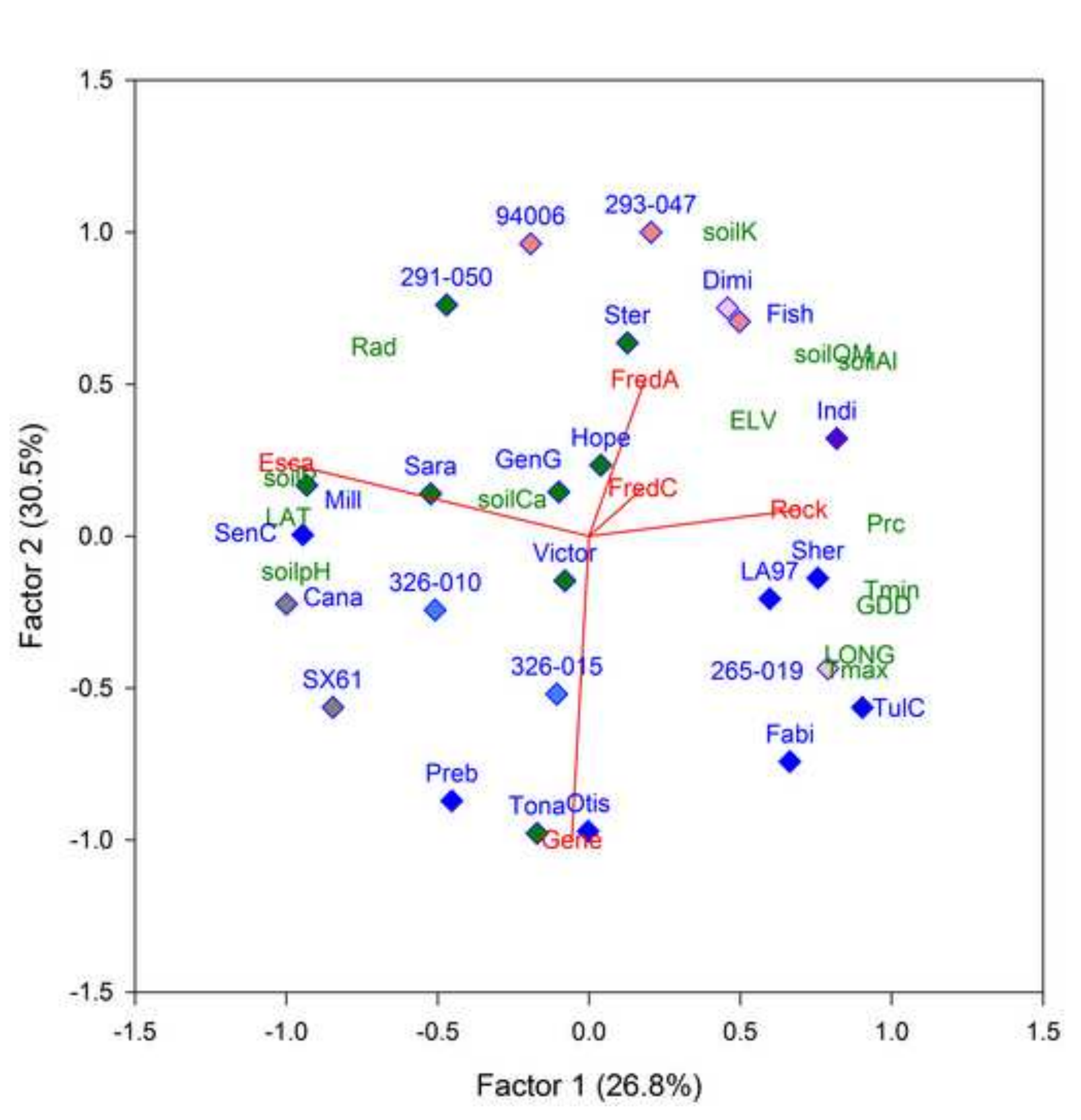

Figure 4

\section{Figure}

4

